\title{
Differential Impact of Flavonoids on Redox Modulation, Bioenergetics, and Cell Signaling in Normal and Tumor Cells: A Comprehensive Review
}

\author{
Asimina Kerimi and Gary Williamson
}

\begin{abstract}
Significance: Flavonoids can interact with multiple molecular targets to elicit their cellular effects, leading to changes in signal transduction, gene expression, and/or metabolism, which can, subsequently, affect the entire cell and organism. Immortalized cell lines, derived from tumors, are routinely employed as a surrogate for mechanistic studies, with the results extrapolated to tissues in vivo.

Recent Advances: We review the activities of selected flavonoids on cultured tumor cells derived from various tissues in comparison to corresponding primary cells or tissues in vivo, mainly using quercetin and flavanols (epicatechin and (-)-epigallocatechin gallate) as exemplars. Several studies have indicated that flavonoids could retard cancer progression in vivo in animal models as well as in tumor cell models.

Critical Issues: Extrapolation from in vitro and animal models to humans is not straightforward given both the extensive conjugation and complex microbiota-dependent metabolism of flavonoids after consumption, as well as the heterogeneous metabolism of different tumors.

Future Directions: Comparison of data from studies on primary cells or in vivo are essential not only to validate results obtained from cultured cell models, but also to highlight whether any differences may be further exploited in the clinical setting for chemoprevention. Tumor cell models can provide a useful mechanistic tool to study the effects of flavonoids, provided that the limitations of each model are understood and taken into account in interpretation of the data. Antioxid. Redox Signal. 29, 1633-1659.
\end{abstract}

Keywords: quercetin, glucose, hepatocyte, HepG2, cancer

\section{Introduction, Scope and Aims of This Review}

$\mathbf{P}$ OLYPHENOLS CONSTITUTE A LARGE GROUP of molecules found in plants, and are present in all diets, especially those high in fruits, vegetables, and plant-based products such as coffee and tea. The group includes isoflavones such as daidzein and genistein from soy, stilbenes such as resveratrol, phenolic acids such as the chlorogenic acid group found in coffee and fruits, and the flavonoids, subdivided into flavonols, of which quercetin is the most studied, flavanols, such as epicatechin and related compounds, found at high levels in green tea, flavanones, especially hesperidin from orange juice, and anthocyanins from berries. This review will focus on flavonoids, where most of the work reported in the literature related to mechanisms of action on tumor cells is on quercetin and epicatechin (including green tea catechins such as (-)-epigallocatechin gallate [EGCG]).

Quercetin has been tested in several animal models of carcinogenesis, often co-administered at a high dose together with a strong cancer-promoting agent or in a model of cancer development, and the results do not always indicate a protective effect. For example, in rats treated with

School of Food Science and Nutrition, University of Leeds, Leeds, United Kingdom.

(C) Asimina Kerimi and Gary Williamson, 2017; Published by Mary Ann Liebert, Inc. This Open Access article is distributed under the terms of the Creative Commons Attribution Noncommercial License (http://creativecommons.org/licenses/by-nc/4.0), which permits any noncommercial use, distribution, and reproduction in any medium, provided that the original authors and the source are cited. 
nitrosomethylurea to generate pancreatic cancer, quercetin promoted carcinogenesis (16). In contrast, when benzo(a)pyrene was used to generate lung cancer in Swiss albino mice, quercetin supplementation exerted a protective effect against cancer development, but crucially as a guide for mechanism of action, the effect was much more pronounced when quercetin was given as a chemopreventive agent rather than as a chemotherapeutic agent (110). When female ACI rats were given quercetin $(2.5 \mathrm{~g} / \mathrm{kg}$ food $)$ for 8 months, there was no protection against breast cancer (224), but quercetin together with doxorubicin increased anti-tumor activity in mice with 4T1 breast cancer (63). These examples indicate that it is difficult to draw any general conclusions, and, therefore, specific animal studies are incorporated into the main body of the review when and where appropriate.

In humans, several trials have tested the efficacy of flavonoids on cancer risk and progression. A phase I trial of quercetin has been reported (71), and trials with flavonoids on cancer progression in cancer patients in phase I and II clinical trials have been reviewed (242). Epidemiological studies report that intake of quercetin-rich food reduced the risk of gastric cancer by $43 \%$ (66) and of colon cancer by $32 \%$ (241). Widely reported effects of quercetin have led to claims that high concentrations can inhibit the growth of cancer cells, and hence could aid chemoprevention.

Green tea is the most studied chemopreventive agent and so far, results obtained show some promise for further studies. In a study of more than 8000 individuals, daily consumption of green tea demonstrated delayed cancer onset; further, breast cancer patients experienced a lower recurrence rate and longer remission (73). However, high doses of green tea, generally above that possible to be obtained from the diet alone, that is, as a supplement in the form of an extract, may cause hepatotoxicity in some individuals $(21,108,151$, 177). It is highly doubtful whether nutritional doses could ever achieve a high enough concentration in blood or other tissues required to exert this effect (167). Very high transient blood concentrations can be achieved by pharmaceutical doses or by direct intravenous administration, as shown for quercetin (90). These factors must be addressed in any study proposing to use flavonoids, at dietary or pharmacological doses, as agents to reduce the risk of cancer or, indeed, of any chronic disease.

When considering the interaction of any molecule, whether a flavonoid, other phytochemical, nutrient, drug, or toxin, with a target, the absorption, metabolism, and excretion must be considered. The process of absorption can substantially modify the chemical structure of the parent molecule and, hence, change the nature of the compound encountered by the cell or tissue of interest. Pathways of flavonoid metabolism have been extensively reviewed (55), and will not be presented in detail here, but will be considered where directly relevant to the issue discussed. Quercetin bioavailability has been widely reported and is well understood; the interaction of quercetin and epicatechin with the intestine, leading to absorption, is summarized in Figure 1. Quercetin, epicatechin, and EGCG pharmacokinetics have been documented in detail and reviewed in humans $(42,43$, 55 ), and the pathways of metabolism and excretion in the urine are adequately established $(143,157,189)$. The areas that lack some important information concern the interaction of polyphenols with the gut microbiota, whereas the full profile of metabolites arising from gut microbiota catalysis has not yet been fully described in detail (188, 194, 228, 263). Typical concentrations of flavonoids and their gut microbiota-metabolites in blood have been reported in

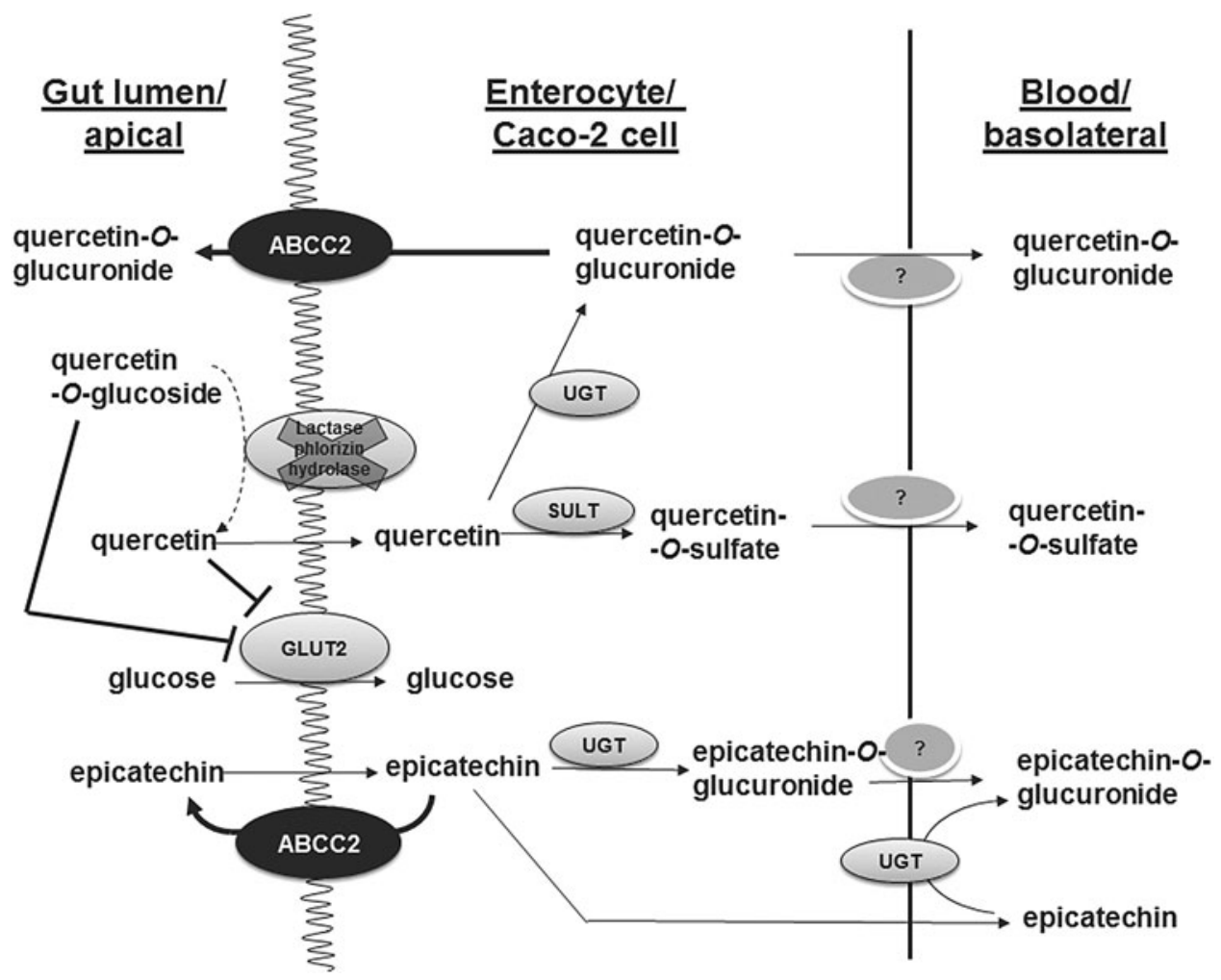

FIG. 1. The metabolic reactions of quercetin and epicatechin in small intestine enterocytes and in differentiated Caco-2 cells, which, ultimately, lead to absorption and bioavailability. The uptake of glucose can also be attenuated by polyphenols at this site via inhibition of glucose transport. GLUT, glucose transporter; UGT, uridine diphosphate glucuronosyl transferase; SULT, sulfotranferase. 
numerous publications after consumption of flavonoids from foods, supplements, or pharmaceutical preparations in both animals and humans in vivo $(55,143,195,263)$. Nevertheless, it is difficult to make a direct comparison between in vivo and in vitro concentrations, but some guidelines have been given $(55,125,143,262)$. When considering the extrapolation from animal pre-clinical studies to human intervention studies, we can use hesperidin as an example. If we assume that the concentration achieved in plasma is a suitable target comparison, then $\sim 15 \mathrm{mg}$ (aglycone equivalents) $/ \mathrm{kg}$ body weight administered to rats gave rise to a $\sim 0.6 \mu M$ peak concentration in plasma (149), whereas a much lower dose per kilogram body weight of $50 \mathrm{mg}$ (aglycone equivalents)/ $70 \mathrm{~kg}$ to humans gave a similar concentration $(\sim 0.5 \mu M)$ in plasma (143). It is also possible to take the approach we have recommended earlier (117), where the strategy is to first show an effect in humans, and then demonstrate the mechanism. In this way, arguments about which in vitro concentration to choose become less important since the effect is already demonstrated in vivo, and the goal of the in vitro experiments is to elucidate the mechanism, rather than prove the effect.

The first and critical step of any interaction of a flavonoid with a cell is consideration of the primary target. Several high-affinity molecular targets have been identified, which could trigger subsequent cellular events. In addition, if the target is intracellular, the flavonoid or derivative must enter the cell to reach it, by either passive diffusion or transporterfacilitated processes. Clearly, the expression of such transporters and target proteins is vital to enable the flavonoid to exert an effect, and, therefore, relative expression of these molecules in normal and tumor cells is important. Flavonoids will interact differently in various types of cells and tissues given the diverse profile of the required transporters, affecting their bioavailability and the abundance of their molecular targets and downstream effectors required to realize an effect. Based on these aspects, this review addresses two questions: To what extent can the effect of flavonoids on tumor cell models be extrapolated to in vivo effects? And, conversely, can flavonoids be used to selectively reprogram or even help to kill tumor cells? To answer these questions, the review will first consider some of the differences between tumor and normal cells that are relevant to flavonoid action, before discussing in more detail reported interactions of flavonoids with molecular targets in both settings.

\section{Examples of Differences Between Tumor and Normal Cells Responsible for Differential Flavonoid Action}

\section{Most commonly used cell models in vitro} to study flavonoid action

Cultured cells are a well-established in vitro experimental system that is extensively used when studying the effects of flavonoids on biological systems. Most of the cell lines used in the lab are immortalized and derived from a tumor tissue, which are then passaged, cultured, grown, and often differentiated. The latter retain functional aspects of their original phenotype. Human Caco-2 and Caco-2/TC7 cells have been isolated from the colon but are used as a model for the small intestine, as after the differentiation of confluent cultures, they form microvilli and express some small intestinal brush border marker enzymes such as sucrase. In conjunction with human studies, they constitute an indispensable proxy for absorption, disposition, metabolism and excretion studies of numerous drugs and phytochemicals, including flavonoids, and have been extensively characterized (27, 93, 230, 282, 286). Human cancer-derived HepG2 cells are believed to retain several hepatic functions and are, as such, used for in vitro hepatocellular studies. Various molecular analyses have documented differences to primary hepatocytes (46), and it is now becoming apparent that their glycolytic nature may be responsible for their failure to replicate effects reported in culture in human liver tissues in vivo or in hepatocytes ex vivo after liver tissue resection. Human MCF-7 and MDA-MB-231 cells have been commonly used as models for human breast cancer, and, given the lack of human cells, mouse INS-1 cells are one of the main lines studied as a model for pancreatic cells.

For tumor cells both in vivo and in vitro, the profiles of gene expression, transporters, and signaling pathways are somewhat different to normal cells. Tumor cells are cultured in vitro to provide a model for hepatotoxicity and chemoprevention studies. In some cases where tumor cells retain substantial characteristics of their original phenotype, they are used to provide information on mechanisms of action, which can then be extrapolated to the whole organism in vivo. Nonetheless, culturing practices, for example, concentration of nutrients in the medium, repetitive sub-culturing, culture vessel/material, length of differentiation, oxygen availability, and consistency between different batches can lead to significant interlaboratory differences in observed effects and further complicate interpretation of reported data in the literature (4). Moreover, the concentration of the flavonoid employed is important. The intestine is exposed to high concentrations of flavonoids after oral ingestion, where millimolar concentrations can be found, whereas after absorption in the intestine, the maximum concentration is only a few micromolar. This also needs to be taken into account in the design of in vitro experiments, and when studying different cell types.

\section{Differences in gene expression between normal and tumor cells}

Transporter differences between Caco-2 cells and small intestinal tissue. When used as an intestinal in vitro model, Caco- 2 cells are grown on filters for 21 days, and during this period the gene expression of many intestinal enzymes and drug transporters gradually increases (212). Caco-2 cells grown on a plastic support for only 4 days have a lower expression of transporters than cells grown on permeable filters for 21 days (4). Caco-2 cells (and their TC7 clone) provide an excellent example where it is essential to understand the experimental model to appropriately extrapolate results to in vivo. For example, the flavonoid quercetin is bioavailable in humans, and it is absorbed through the small intestine (192) (Fig. 1). The absorption and biological effects of quercetin in humans are the subject of numerous reviews $(55,143,190)$. Quercetin exists in planta as a glycoside, and it is consumed mostly in this form (198). The glucoside is not absorbed intact, but must first be deglycosylated by a brush border enzyme, lactase phlorizin hydrolase (LPH) (52). This enzyme is highly abundant in the small intestine, but it is almost absent on the brush border of Caco-2 or Caco-2/TC7 cells $(36,207)$ (Fig. 1). Consequently, although Caco-2 or Caco-2/TC7 cells can be used as a model to examine the 
absorption or biological effects of quercetin as an aglycone, they cannot be used to examine the action of quercetin glycosides, or, indeed, any other phytochemical bound to a sugar moiety; this includes plant extracts where the active components are glycosylated. An exception is where a flavonoid glucoside can interact directly with proteins on the brush border surface as in the case of the sugar transporter glucose transporter (GLUT)2, to which some flavonoid glucosides bind and inhibit its glucose-transporting activity (114) (Fig. 1). This interaction involves direct binding to attenuate sugar transport, whereas the flavonoid glucoside itself is not a substrate of the transporter (79). In general, the absence of LPH in the cell model is clearly less important when the protein target is expressed on the surface of the cell and the glycoside can interact directly without prior deglycosylation being a requirement.

The transporter ABCC2 (Fig. 1) is higher in Caco-2 cells compared to intestinal enterocytes (68). This indicates that intestinal efflux of conjugated flavonoids will be emphasized in the cell model, and, hence, measured absorption will appear to be less than in the normal tissue. On the other hand, the conjugating enzymes, sulfotransferase (SULT) and uridine diphosphate glucuronosyl transferase (UGT), are present in both small intestinal enterocytes and Caco- 2 cells, and so conjugation will occur in both. However, the profile of these phase II enzymes is different, not only between Caco-2, Caco2/TC7 cells, and enterocytes, but also between the duodenum, jejunum, and ileum, and so the exact rates of conjugation and the profile of products will depend on the exact distribution and the enzyme specificities, which vary for each flavonoid and enzyme combination. For example, UGT8 and UGT9 are the most active on epicatechin, followed by UGT1A1 (285), and so the exact rate of conjugation will depend on the expression of these three isoforms. In the small intestine, $1 \mathrm{~A} 1$ is high, with 1 A8 and 1 A9 10-fold lower (181).

These examples highlight the complexity of using cultured immortalized cells for studies on flavonoids, indicating that appropriate interpretation of experimental data depends on a detailed underlying knowledge of the characteristics of the cellular system.

Flavonoid transporter differences between HepG2 cells and hepatocytes. Small-molecule effectors can interact with a cell by binding to surface proteins or by entering the cell by active, facilitated, or passive transport. Sufficiently hydrophobic and relatively small molecules, such as quercetin, epicatechin, and many synthetic drugs, can enter cells by passive diffusion and do not rely on active transport. In many cases, the concentration gradient for diffusion is maintained by further metabolism of the molecule once inside the cell. However, hydrophilic molecules such as glucose cannot enter cells by passive diffusion and are instead transported into the cell by transporters. These include a range of GLUTs, which are facilitative transporters and do not require energy (114), and additionally in the intestine and kidneys by sodium-dependent active transport (99). The profile of GLUTs is different in normal and tumor tissues, leading to potential differences in energy metabolism. In normal hepatocytes, GLUT2 is the main transporter, and this insulin-responsive transporter is translocated to the cell surface to allow glucose uptake when high concentrations are present, such as post-prandially after a sugar-containing meal. Hepatocytes also express GLUT10,
GLUT9, and GLUT3 (111). The main functional GLUTs in HepG2 cells are GLUT1, which is highly expressed in many tumor cells, and GLUT9 (234); GLUT2 is expressed, but it may be localized internally (94), and GLUT3 mRNA is also highly expressed (Fig. 2). Even though GLUT1 is expressed at notably elevated levels in human cancers, it remains the rate-limiting step for glucose transport into cancer cells, and high expression is correlated with poor patient survival in most solid tumors (253). A summary of some of the differences described earlier in glucose utilization between hepatocytes and HepG 2 cells is shown in Figure 3, and the distribution of GLUT transporter mRNA in hepatocytes and HepG2 cells is shown in Figure 2.

Attachment of a sugar or glucuronide moiety to a flavonoid such as quercetin prevents passive diffusion by increasing size and decreasing hydrophobicity (Fig. 1). The conjugation of flavonoids by phase II metabolism has been well documented (55), and the exact compounds in blood have been reported $(1,167)$. For the conjugates to enter cells, they must travel either by passive diffusion, which is slow for conjugates such as glucuronides and sulfates, or more rapidly by transporters such as organic anion transporter (OAT) (SLC22A family) or organic anion-transporting polypeptides (SLCO family) $(9,265,266)$. The expression of these transporters is different between normal and tumor cells, and since OAT expression can be downregulated in the latter, the uptake of flavonoid conjugates into cells would be lower in cultured cells compared with normal cells in vivo (Fig. 2). In addition, many cancer cells show drug resistance (159), and have extremely high levels of efflux transporters, such as the ATP-binding cassette (ABC) transporters, which actively transport conjugated molecules, such as flavonoids and drugs, out of the cells. Elevated expression of P-glycoprotein (ABCB1) (38) and of multidrug resistance-associated protein (MRP)2 (ABCC2) $(82,124)$ is responsible for the reduced effectiveness of many anti-cancer drugs, although some lines of research argue that MRP2 is partially located intracellularly in all the cell lines, and even when overexpressed in HEK293 cells may remain intracellular and not be functional at the plasma membrane (4). Cancer cell lines generally have much lower levels of cytochrome P450s. For example, CYP1A2 is high in hepatocytes but absent in HepG2 cells, whereas HepG2 cells still express some, albeit low, of the CYP1A1 isoform. Because of these differences in CYP expression, hepatocytes are better than HepG2 cells for studying biotransformation of drugs and flavonoids. However, the response of xenobiotic metabolizing enzymes to inducers is similar in hepatocytes and HepG2 cells (260). Catechol- $O$ methyltransferase (COMT), the enzyme that methylates flavonoids containing a catechol group, is very high in both HepG2 cells (255) and in liver (92) (Fig. 2).

These transporter expression differences undermine the usefulness of cultured cells to study the effect of the relevant molecules such as flavonoid conjugates, and to more closely represent the situation occurring in vivo. Any exposure of cultured tumor cells to flavonoids will be much less effective than exposure to normal cells, since efflux transporter overexpression will remove the flavonoid (as conjugate) from the cell very rapidly compared with normal cells. In addition, in vivo, flavonoid conjugates, as reported for quercetin, may be deconjugated and therefore activated near sites of inflammation $(75,156,239)$. Further, monocarboxylate transporter (MCT)1, which transports lactic and pyruvic acids and hence 
FIG. 2. Comparison of mRNA expression of selected transporters and enzymes relevant to flavonoid action and metabolism in human hepatocytes and HepG2 cells. Data were obtained by using hepatocytes from six volunteers and from cultured HepG2 cells by using real time RT-PCR according to (92). ABC, ATP-binding cassette; COMT, catechol- $O$-methyltransferase; CYP, cytochrome P450; NQO1, quinone reductase oxidoreductase; RT-PCR, reverse transcriptase-polymerase chain reaction.

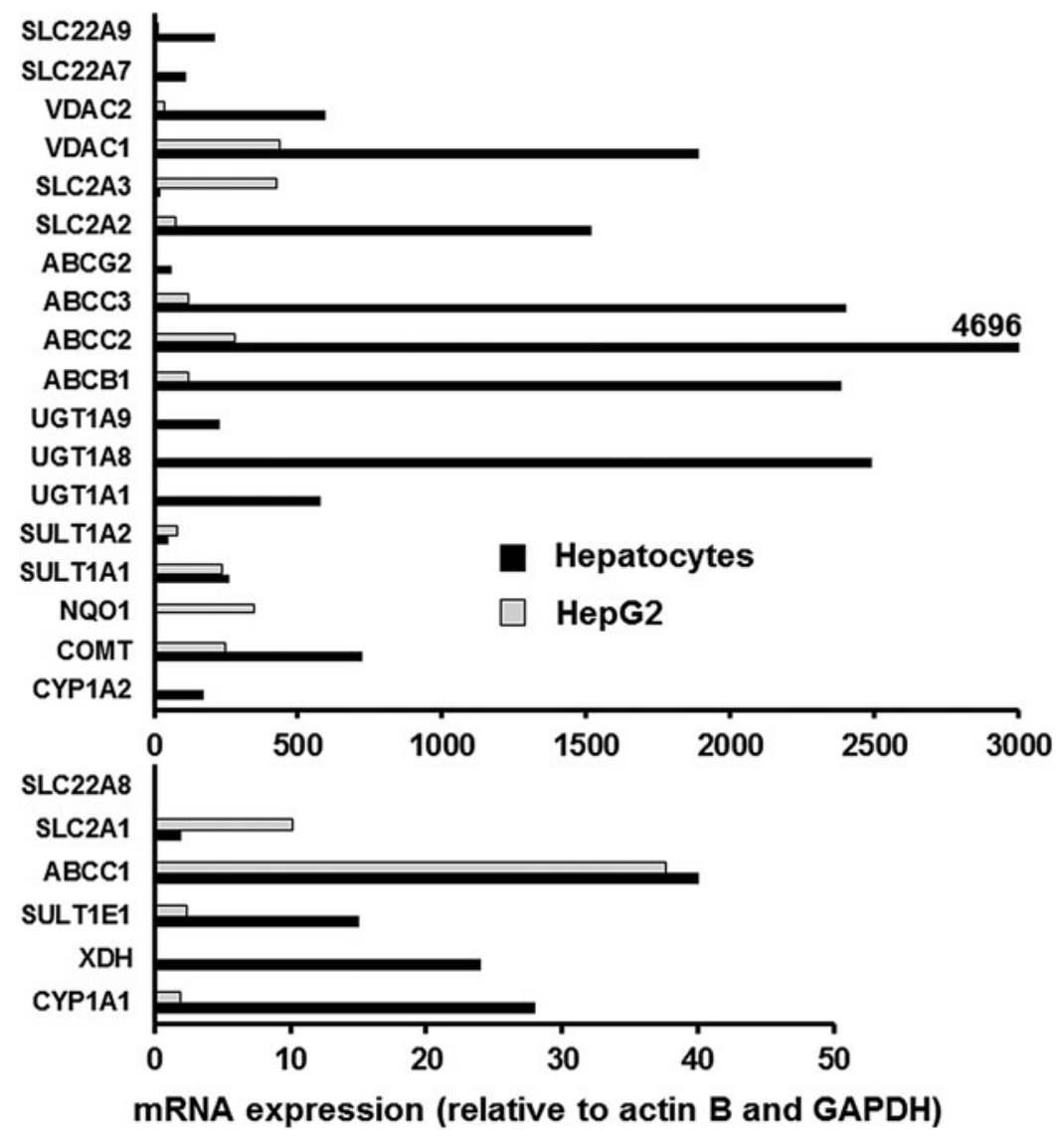

FIG. 3. Illustrative metabolic differences between glucose utilization in hepatocytes and HepG2 cells. Information summarized from data presented and discussed in this review. HIF-1 $\alpha$, hypoxiainducible factor- $1 \alpha$; NOX, NADPH oxidase; Nrf2, nuclear factor (erythroid-derived2)-like 2; PDC, pyruvate dehydrogenase complex; ROS, reactive oxygen species; TCA, tricarboxylic acid.
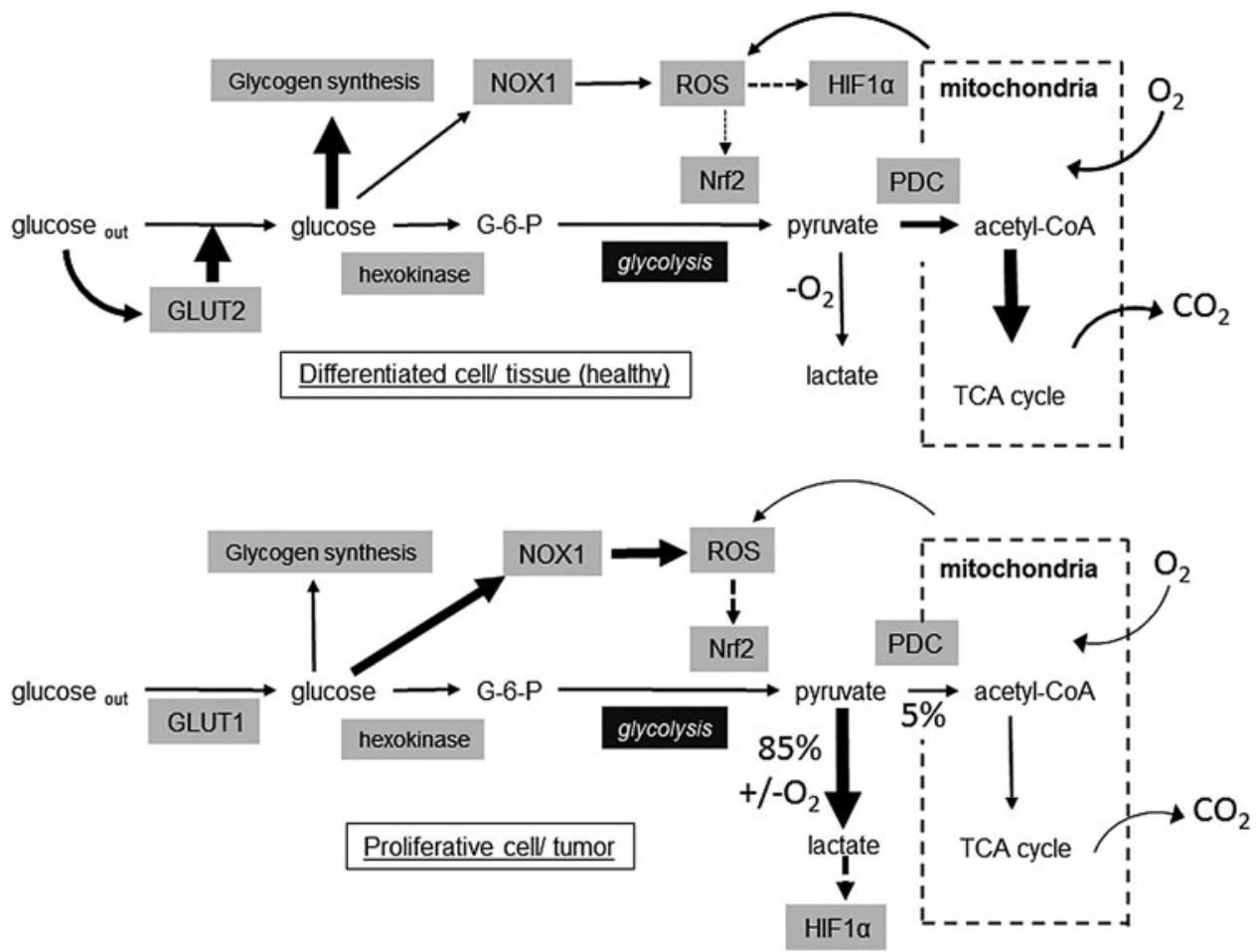
is of importance in glycolysis and gluconeogenesis, is highly expressed in most immortalized cell lines in terms of both gene and protein expression, and was also found to be functional in five out of six investigated cell lines, including HepG2, Caco2, and Caco-2/TC7 cells (4). In general, MCT1 accepts shortchain monocarboxylates and small drugs with carboxylate groups such as salicylate as substrates, suggesting that care should be exercised when investigating small monocarboxylate compounds. It is fortunate that very few drug substrates have been identified for MCT1 (158), whereas inhibition of MCTs has been proposed as a therapeutic strategy to target metabolic pathways in cancer through blocking pyruvate metabolism, in addition to their effects on lactate efflux pathways (57).

In summary, differences in transporter expression between normal and tumor cells can substantially alter the interaction of a flavonoid with cellular processes, and in some cases, may prevent or diminish the flavonoid reaching a molecular site of action.

\section{Metabolic differences between normal and tumor cells that could affect interactions with flavonoids}

General metabolic differences between normal and tumor cells and redox status. Metabolic differences in energy storage and utilization are critical when considering the response of normal and tumor cells to effectors such as glucose, drugs, and phytochemicals, including flavonoids. As the major fuels for mitochondrial substrate oxidation to harness energy in the form of ATP, glucose and fatty acids compete with each other at the level of the pyruvate dehydrogenase complex (PDC). PDC is usually active in most healthy tissues in the well-fed state, and suppression of PDC by pyruvate dehydrogenase kinases (PDKs) is crucial to spare pyruvate and other three carbon substrates when glucose is low, termed metabolic flexibility.

Tumor cells, in general, exhibit several metabolic adaptations that allow them to grow rapidly, such as unregulated uptake of glucose mainly through GLUT1, increased anaerobic glycolysis with excess lactate production, and lowered mitochondrial ATP generation through the electron transport chain and oxidative phosphorylation (OXPHOS), processes that are collectively termed the "Warburg effect." In addition to glycolysis, cancer cells also shunt glycolytic intermediates into the pentose phosphate pathway, serine biosynthesis, and lipid biosynthesis, as opposed to complete oxidation by mitochondrial respiration, and so efficiently generate NADPH, another factor that is essential for biosynthetic processes to enable cancer cell survival (32). In some tumors, this is achieved by limiting pyruvate utilization by mitochondria. Many cancer cells can also use alternative sources of energy such as amino acids, fatty acids, and lactate. Glutamine has been identified as a critical nutrient for cancer cells for glutathione synthesis and to replenish tricarboxylic acid (TCA) cycle intermediates for the biosynthesis of lipids and mitochondrial ATP production, complementing the altered state of glucose metabolism. Glutaminase inhibition led to cell cycle arrest similar to peroxisome proliferator-activated receptor (PPAR) $\gamma$ activation through modulation of reactive oxygen species (ROS) in lung cancer cells, and both $\beta$ oxidation and PDKs were found to be essential in the sequence of events (226).
The importance of these anaplerotic reactions for cancer cell survival is such that in cells derived from solid tumors undergoing loss of attachment (LOA) to the extracellular matrix, inhibition of glucose uptake and catabolism results in the loss of ATP and NADPH as a result of decreased flux through the pentose phosphate pathway. Under LOA conditions, characterized by high ATP demand, production of ROS is increased and linked to upregulation of antioxidant mechanisms and reactivation of fatty acid oxidation requiring maintenance of redox balance (32). An enhanced antioxidant response and increased detoxification capacity in subgroups of melanoma and lymphoma have been previously identified and characterized by high OXPHOS activity $(31,138,245)$. More specifically, in lymphoma, the authors reported higher levels of reduced glutathione in the OXPHOS subgroup compared with the non-OXPHOS subgroup (31). Similarly, in melanoma, ROS levels were reduced in the OXPHOS subgroup due to enhanced ROS detoxification capacities mediated by PPAR $\gamma$ coactivator $1 \alpha($ PGC- $1 \alpha)(245)$. A dual capacity of tumor cells for glycolytic and OXPHOS metabolism has been put forward, redefining the "Warburg effect" and increasingly supporting the idea that it is the physiological stresses, dictated by the cancer microenvironment such as the lack of oxygen, which are the main drivers of the metabolic switch in tumor cells (80).

Mitochondrial function is responsible for the majority of oxygen consumption, accounting for $70 \%-90 \%$ of total oxygen consumption within the cell, whereas constant supply of electron donors (e.g., NADH) constitutes an important factor regulating mitochondrial respiration. Higher respiration rates are linked to higher levels of mitochondrial ROS production and may lead to increased proton leak and a drop in mitochondrial membrane potential in healthy cells (60). Poorly formed blood vessels in tumors constitute a bottleneck that limits oxygen supply to the growing tumor $(211,244)$. Oxygen consumption within the tumor causes an imbalance resulting in hypoxia and activation of downstream events, whereas the severity of the response is dependent on the level of oxygen deprivation (37). With respect to tumor growth characteristics, moderate hypoxia causes a slowing of tumor cell proliferation whereas severe hypoxia causes outright cell death (185). Regulating the redox potential by restricting mitochondrial respiration as well as low levels of electron donors will activate AMP-activated protein kinase (AMPK) and other related energy sparing pathways. This will lead to metabolic adaptation and improved metabolic status for the healthy tissue, and increased oxidative stress leading to senescence of cancer cells through restriction of biosynthetic pathways at the early stages of cancer chemoprevention. However, AMPK activation in the solid tumor microenvironment could enhance cancer cell survival through inhibition of fatty acid synthesis and preservation of NADPH (109). It comes as no surprise that AMPK has long been a target of cancer drug research and quercetin in that light is viewed as a beneficial agent (96).

Reducing hypoxia by decreasing oxygen consumption restores tumor growth in most cases of established cancers, with a compensatory increase in glycolysis. Anaerobic glycolysis is advantageous to cancer cells for survival under hypoxic conditions. In normal cells, ROS stemming from mitochondrial OXPHOS activate and stabilize hypoxiainducible factor $(\mathrm{HIF}-1) \alpha$, inducing downstream controlled 
genes that stimulate anaerobic glycolysis to minimize the mitochondrial ROS-producing burden, and to mobilize antioxidant defenses. In cancer cells and especially in solid tumors where hypoxia is maintained, HIF- $1 \alpha$ remains abnormally stabilized, and through upregulation of glycolytic enzymes and long-term inactivation of the PDC complex, owing to increased expression of PDKs (PDK1), reduced levels of ROS protect cancer cells from apoptosis $(25,26)$. In addition, glycolytic metabolites such as lactate and pyruvate also stabilize HIF-1 $\alpha$ via a hypoxia-independent mechanism and establish a positive loop of HIF- $1 \alpha$ activities, suggesting that obesity or insulin resistance could increase the development of cancers (57). Hypoxia in tumors also leads to overexpression of HIF- $2 \alpha$, which, subsequently, favors cancer cell survival, proliferation, and metastasis involving noncanonical glutamine metabolism as recently shown in human pancreatic ductal adenocarcinoma (PDAC) $(76,136)$.

Generally, ROS/RNS interact with certain amino acid residues of proteins (protein tyrosine phosphatases, protein tyrosine kinases [PTKs], and protein kinase $\mathrm{C}$ [PKC]) and, in turn, activate downstream kinase cascades such as phosphoinositide 3-kinase (PI3K) and mitogen-activated protein kinases (MAPKs). PTKs have been found to be hyperactivated in many cancer cells and are regarded as oncoproteins, whereas activation of the c-jun-N-terminal kinase (JNK) signaling pathway involving nuclear factor kappa-light-chain-enhancer of activated B cells $(\mathrm{NF}-\kappa \mathrm{B})$ and MAPKs in cancer and inflammation are also linked to increased blood lactate levels through inactivation of the PDC complex (187).

Modulation of such metabolic pathways has for many years been the objective of various studies in an effort to maximize chemoprevention by altering the redox state of cancer cells without affecting healthy tissue. In that direction, PDKs are seen as potential molecular targets in antiglycolytic therapies for cancer, whereas in various cancer cell lines, inactivation of PDKs, by either chemical or molecular approaches, has led to an increased activity of PDC (19). In contrast, mining of microarray data from human tumor data sets has shown that PDK4 is commonly downregulated in tumors compared with their tissues of origin, whereas PDK1 expression is always high in liver metastases and either low or high at the primary tumor site. This suggests that the metabolic switch influencing tropism of cancer cells may occur when they acquire metastatic properties (64), pointing to differential regulation by distinct pathways in different cell types and suggesting varying dependencies on PDH flux between normal and transformed cells (89).

Currently, the diverse metabolic signatures of different cancers, the anaplerotic mechanisms that may be activated, depending on the stage of the cancer and the proliferation stage of the specific cancer in question, are posing a great challenge for cancer therapeutics. In an effort to achieve breakthroughs in drug discovery, research has expanded to devise a plethora of different inhibitors and combined therapies to halt cancer progression at the different stages (examples shown in Fig. 7) and polyphenols in that light are believed to have a role to play.

Metabolic differences between HepG2 cells and hepatocytes that could affect interactions with flavonoids. Hepatocytes generate a substantial proportion of their ATP through mitochondrial action, and high glucose may overload the elec- tron transport chain in mitochondria, especially through leakage of complex I (193). Highly proliferative cells such as HepG2 generate most ATP by glycolysis, even though they have sufficient oxygen and normal, functional mitochondria, and cancer cells are resistant to compounds that impair mitochondrial activity (146). In normal hepatocytes, GLUT2 responds to high glucose and insulin, and it increases glucose uptake after, for example, a carbohydrate-rich meal $(65,197)$. However, differences in GLUTs discussed earlier lead to unregulated glucose uptake in HepG2 and other tumor cell lines. HepG 2 cells retain some insulin responsiveness, but chronic high-glucose treatment of HepG2 cells leads to modified energy metabolism, through increased PDC E1 $\alpha$ subunit protein and mRNA and increased total PDC activity (236), and also to insulin resistance, which includes loss of insulin-induced Akt phosphorylation and increased phosphorylation of insulin receptor substrate-1 (IRS-1) (174).

In vivo, chronically elevated plasma glucose leads to enhanced levels of intracellular ROS, insulin resistance, and perturbed metabolism in the liver, with the metabolic sensors AMPK and SIRT1 downregulated (178). In cultured human QZG hepatocytes, high glucose led to increased generation of ROS and lowered cell viability via PKC activation, decreased nuclear factor (erythroid-derived 2)-like 2 (Nrf2) and heme oxygenase 1 (HO-1) protein, and decreased both the phospho-Akt:Akt and the phospho-extracellular signalregulated kinase (ERK):ERK ratios (257). High levels of glucose initially increased mRNA of base excision repair genes in HepG2 cells, and activity of poly[ADP-ribose]polymerase 1, leading to lowered cellular $\mathrm{NAD}^{+}$and insulin receptor phosphorylation, but in the longer term, induced ROS accumulation and DNA damage (184). HepG2 cells express NADPH oxidase 1 (NOX1), which generates ROS under high glucose. NOX1 knockdown led to increased UTP-glucose-1-phosphate uridylyltransferase, which catalyzes the synthesis of UDPglucose, the precursor for glycogen synthesis. Most cultured tumor cells, including HepG2, typically express elevated NOX1 and low rates of glycogen synthesis, enabling them to channel glucose to glycolysis rather than energy storage, to maintain their high energy utilization (18). Increased ROS from NOX1 induce HIF- $1 \alpha$ target genes such as GLUT1 and glucose-6-phosphatase (78). Experimentally, glucose at a very high non-physiological concentration $(>50 \mathrm{mM})$ has also been shown to cause apoptosis in HepG2 cells (35).

High-glucose-induced changes in lipid metabolism are observed in HepG2 cells, such as induced fatty acid synthase (FASN) activity via increased mRNA stability (213), increased accumulation of intracellular storage lipids (276), increased hepatic lipase (243), and changes in intracellular metabolites such as transient increases in glucose-6-phosphate, 3-phosphoglycerate, citrate, and lyso-phosphatidyl choline, and decreases in serine, acylcarnitines, and phosphatidyl ethanolamine (155). All these aspects contribute to tumor progression, and recently, acetyl-CoA carboxylase (ACC) $\alpha$ was reported to have a central role in mediating de novo lipogenesis for metabolic adaptation in human hepatocellular cancer (254). Similarly, de novo lipogenesis activation was also reported in an array of cancer cells following limitation of access to exogenous lipids as may occur in intact tumors (49).

The tumor-specific modulation of carnitine palmitoyl transferase (CPT)1A, the rate-limiting step in $\beta$ oxidation, and of FASN, in human colorectal cancer and breast 
carcinomas, has also been reported. CPT1A was significantly decreased in the cytoplasm of tumorous samples, whereas FASN was increased in addition to a striking CPT1A nuclear localization both in the tumors and in vitro in epithelial neoplastic cells such as MCF-7, Caco-2, and HepG2 (152, 199). A link to histone acetylation and post-translational modifications was also apparent, since a correlation between nuclear CPT1A levels and histone deacetylase activity in tumorous tissues and neoplastic cell lines was reported. Caco- 2 cells, when grown in vitro as colonocytes (without differentiation), preferentially oxidized butyrate instead of glucose as an energy source to produce acetyl-CoA for fatty acid synthesis. Butyrate pre-treated cells displayed a modulation of glutamine metabolism characterized by an increased incorporation of carbons derived from glutamine into lipids and reduced lactate production, reversing their initial highly glycolytic nature linked to PDC deactivation through upregulation of PDK4 involving hyperacetylation of histones at the PDK4 gene promoter level (19).

These phenotypic differences in metabolism may influence the effect of flavonoids on normal and tumor cells, depending on the environment encountered by the cell as defined, for example, by the concentration of glucose used in the medium and the frequency of medium changes, the use of nonessential amino acids, and glutamine that can top up the TCA cycle, in combination with growth factors and fatty acids in the form of fetal bovine serum. Notably, the presence of hepatic cells in vivo in close proximity to macrophages, adipocytes, and other satellite cells with a plethora of diversified signaling functions cannot be mimicked in vitro but can, nonetheless, significantly affect the bioactivity of flavonoids in both healthy and diseased individuals.

\section{Interaction of Flavonoids with Tumor and Normal Cells}

\section{Molecular targets of quercetin and epicatechin}

Direct interactions. Irrespective of the cell physiology, any effect of a small molecule on a cell requires initial interaction with primary targets, followed by subsequent signal transduction and/or gene expression that will lead to functional effects. Although many proteins have been reported to interact directly with flavonoids, the strength of the interaction is critical; only sufficiently strong binding will lead to significant regulation. The crystal structure of several mammalian target proteins bound to quercetin has been reported, and these will form the basis of the interactions that will first be considered here (Fig. 4), followed by discussion of other potentially important targets.

Quercetin competitively inhibits bovine mitochondrial $\mathrm{F}_{1}$-ATPase, an ATP synthase, with an $\mathrm{IC}_{50}$ value of $2-6 \mu M$ (169), and such interaction could lead to numerous changes in
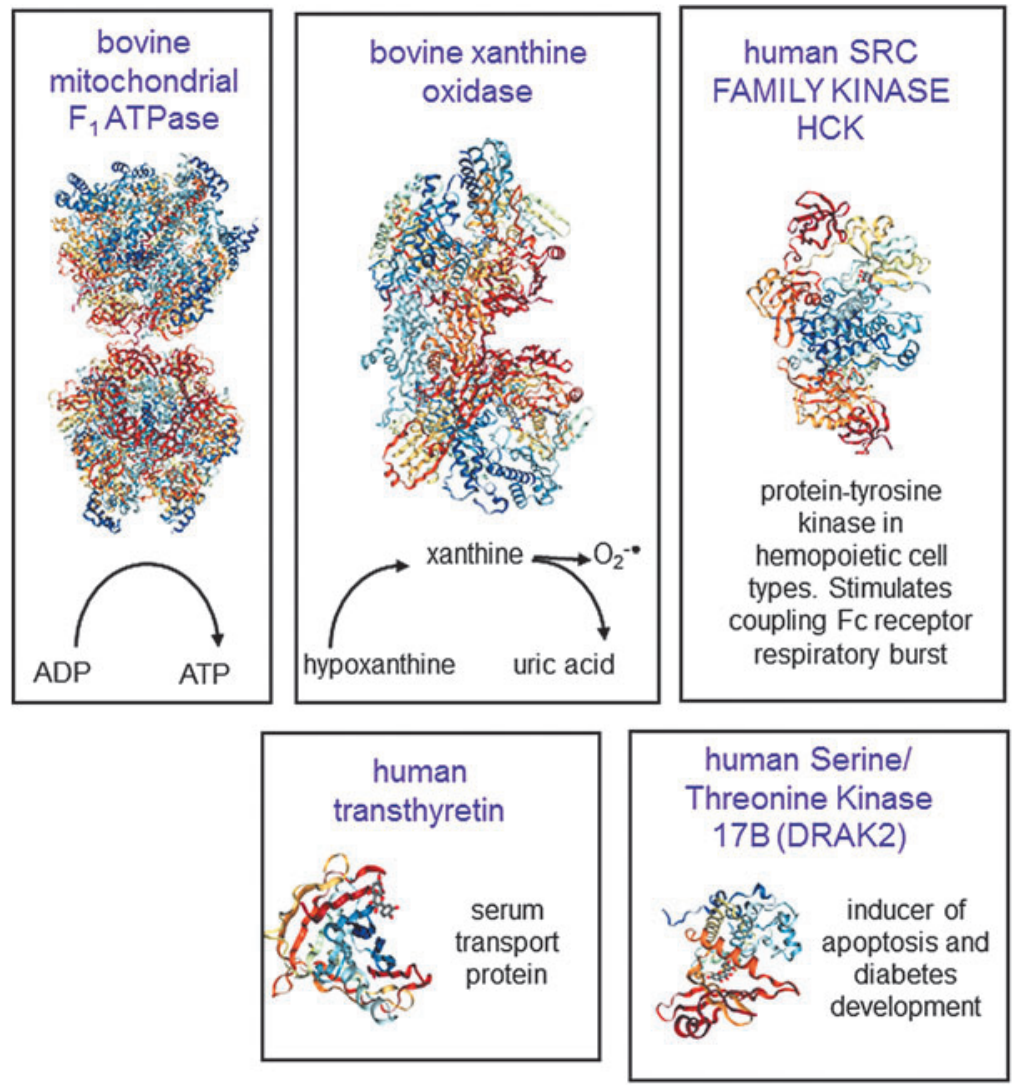

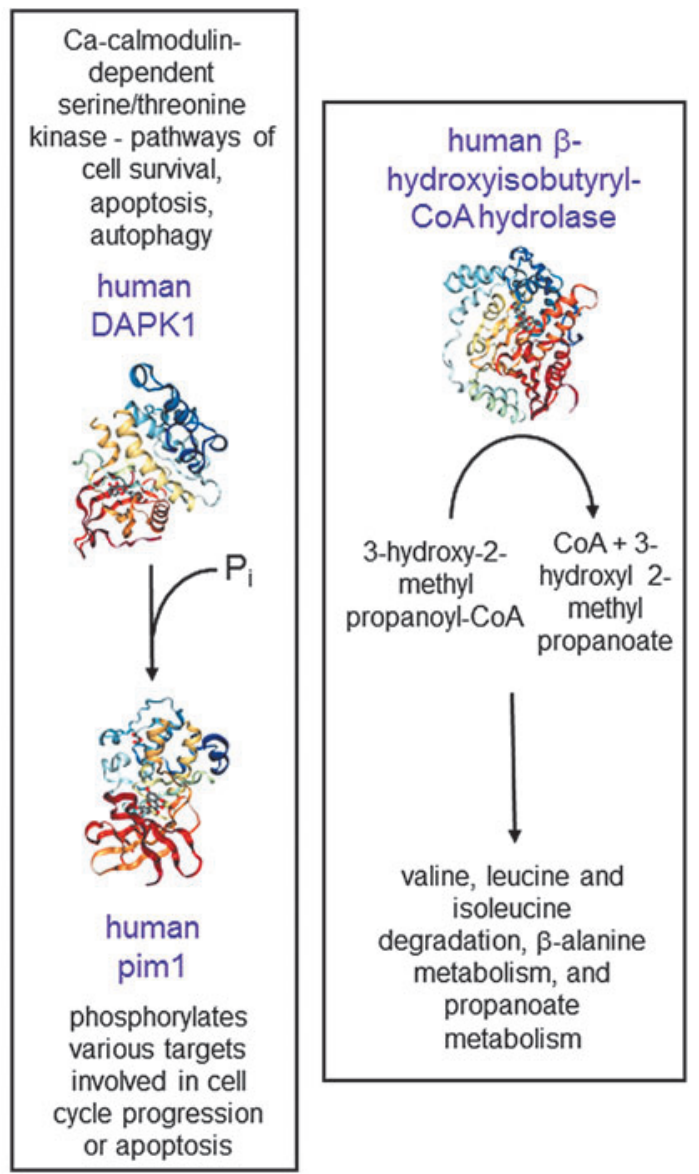

FIG.4. Molecular targets of quercetin. The proteins where crystal structures have been determined in complex with quercetin are shown. The name of the protein is shown in purple, and the function is also indicated. Structures shown are from the PDB (structures 5AUW, 4WNJ, 4LMU, 3NVY, 3LM5, 3BPT, 2JJ2, 2O3P, 2HCK). DAPK1, death-associated protein kinase 1; DRAK2, serine/threonine kinase 17B; PDB, Protein Data Bank. 


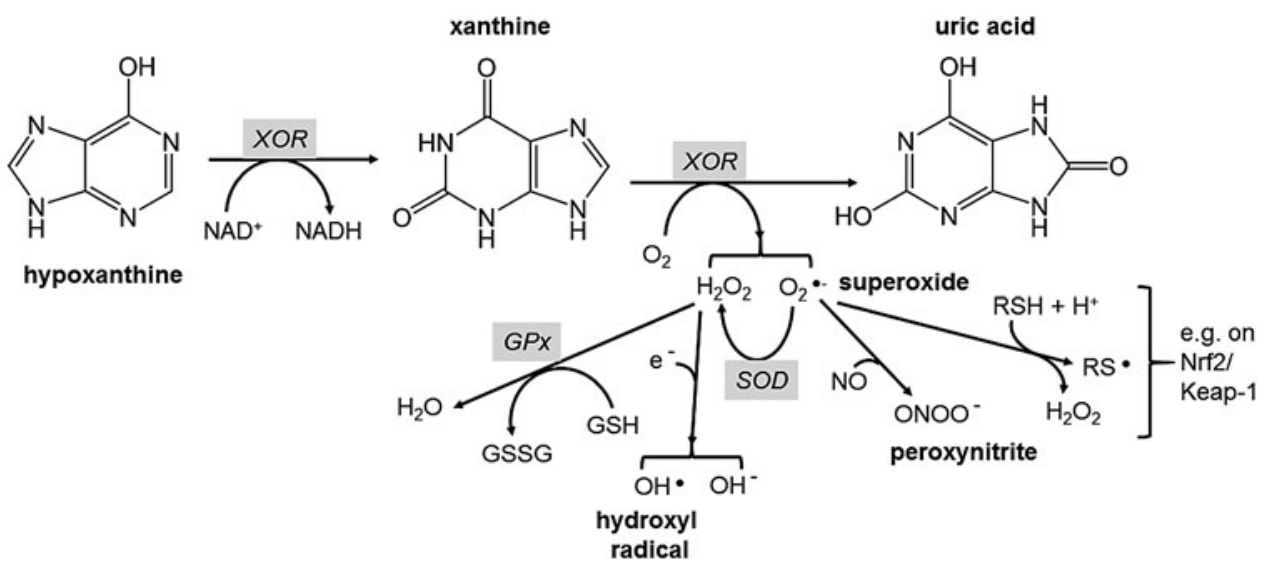

FIG. 5. Reactions catalyzed by XOR leading to ROS and protein thiol oxidation. This large and complex enzyme is a flavin- and molybdenum-containing protein with iron-sulfur centers at the catalytic site. It catalyzes oxidation of both hypoxanthine and the intermediate, xanthine, to form uric acid. Under certain conditions, it produces excess hydrogen peroxide and superoxide $(74,115,182)$, which can then undergo further reactions to generate intracellular ROS. Superoxide can undergo several reactions, including oxidation of thiol groups to produce a thiyl radical and hydrogen peroxide (264), which would account for the activation of Nrf2 by superoxide (183). NO, nitric oxide; XOR, xanthine oxidoreductase.

overall cellular metabolism through secondary effects, since this mitochondrial protein is responsible for synthesizing most of the ATP fueling cellular processes in normal cells. Features of the crystal structure of the protein bound to quercetin show that it inhibits both synthetic and hydrolytic activities of the enzyme (83).

Xanthine oxidoreductase (XOR) is a molybdenum- and flavin-dependent enzyme that produces uric acid from hypoxanthine (Fig. 5). Under certain conditions, it can produce hydrogen peroxide and superoxide radicals, and for example, is the major source of superoxide in plasma after ischemiareperfusion injury (182). Excess uric acid production is, therefore, accompanied by high levels of intracellular superoxide production. As a partial consequence of this, high plasma uric acid, derived from XOR, is also a marker of metabolic syndrome and gout risk (141) whereas mitochondria in cancer cells generate more superoxide anions when compared with their normal counterparts (251). Superoxide is also the primary cause of endothelial dysfunction in high-glucose-treated HUVECs (200). One of the main deleterious effects is the reaction of superoxide with nitric oxide (NO), which not only consumes NO but also produces damaging peroxynitrite (Fig. 5). Peroxynitrite leads to protein damage by nitration, and this reaction contributes, for example, to liver and renal mitochondrial damage in diabetic rats $(137,205)$. Although quercetin and conjugates can react directly with ROS/RNS such as superoxide $(28,240)$ and peroxynitrite (196), and flavonoids are potent chemical antioxidants in many assays (102), the rate of reaction and likely intracellular flavonoid concentrations make it unlikely that such a reaction is biologically significant in vivo $(117,118,220)$. It is more likely that flavonoids affect these processes generating reactive species by attenuating the catalytic rate of XOR and other oxidative enzymes. Quercetin binds to the active site of XOR with a $\mathrm{K}_{\mathrm{i}}$ of $\sim 1 \mu M(29)$, one of the few direct molecular interactions $(51,140)$ that has been shown to have a consequential effect in humans in vivo (215). The crystal structure of XOR complexed with quercetin has been reported (29). The action of flavonoids on XOR is illustrative of the current thinking behind the mechanism of action of flavonoids in vitro. Rather than acting as direct free radical scavengers, they attenuate the activity of some prooxidant enzymes; the damaging effect of these enzymes is mostly apparent only when they are running fast, that is, with high substrate concentration coupled with limiting availability of co-factors such as $\mathrm{NAD}^{+} / \mathrm{NADH}$.

Serine/threonine kinase 17B (DRAK2) is an inducer of apoptosis (153). In pancreatic islet cells from mice overexpressing DRAK2 and fed with a high-fat diet, stimulation with inflammatory cytokines increased apoptosis and led to glucose intolerance and decreased insulin secretion $(77,145)$. DRAK2 plays a role in tumorigenesis, and mediates cyclooxygenase (COX)-2 overexpression in colorectal cancer cells, rendering them resistant to apoptosis (61). Quercetin binds to and interacts directly with DRAK2 $(162,218)$.

Death-associated protein kinase 1 (DAPK1) is a calcium/ calmodulin-dependent serine/threonine kinase that is involved in various cellular signaling pathways triggering cell survival, apoptosis, and autophagy. DAPK1 phosphorylates Pim-1, resulting in inhibition of its catalytic activity, nuclear localization, and cellular function (275). Human Pim-1 is a $\mathrm{Ca}^{2+} /$ calmodulin-regulated serine/threonine kinase, able to phosphorylate different targets, involved in cell cycle progression or apoptosis, and is induced by cytokines (13). Quercetin binds directly to both DAPK1 and Pim-1 (100), indicating its ability to inhibit multiple kinases.

In addition to binding to albumin for transport around the body (24), quercetin also binds to transthyretin, a serum transport protein that is highly expressed in the liver, at a different site to the one for thyroxine T4 (41). Transthyretin amyloidosis constitutes a form of cardiac hypertrophy and is characterized by increased levels of inflammation. Data on the functional effects of quercetin binding to transthyretin are not available in the literature, but such an interaction could potentially increase its local bioavailability. Transthyretin dysregulation has been linked to pre-eclampsia through establishment of hypoxic conditions (85). 
The enzyme 3-hydroxyisobutyryl-CoA (HIB) hydrolase is found predominantly in the liver, heart, and kidney, and it converts HIB to free CoA and 3-hydroxyisobutyrate, which can be a precursor for hepatic gluconeogenesis. The enzyme also has roles in valine, leucine, and isoleucine degradation, $\beta$ alanine metabolism, and propanoate metabolism $(97,217)$. The activity of the enzyme is lower in livers with cirrhosis or hepatocellular carcinoma, suggesting a decrease in the capability of detoxifying HIB (105). Cirrhosis resulted in a significant decrease in HIB hydrolase activity and the branched chain amino-acid pathway, but it had no effect on citrate synthase activity. This suggests that the decrease in HIB hydrolase activity does not reflect a general decrease in mitochondria, but it may contribute to cellular damage, culminating in liver failure (238). Valine catabolism is unique compared with the other branched chain amino-acid pathways as the potentially toxic compound, methacrylyl-CoA, is formed as an intermediate, having considerable potential for cytogenic, mutagenic, and clastogenic actions (216). Quercetin interacts with the enzyme and forms a complex (Fig. 4); however, binding constants are not available in literature. Interestingly, tolcapone, a potent inhibitor of COMT for the treatment of Parkinson's disease, was found to have hepatotoxic effects due to off-target binding to HIB hydrolase, whereas no binding was seen for the less toxic COMT inhibitor entacapone. The mitochondrial toxicity profile of tolcapone, entacapone, and two other novel COMT inhibitors was consistent with the off-target interaction profile of the compounds, supporting the hypothesis that HIB hydrolase is a candidate off-target underlying related mitotoxicity of the drugs (248). Given the fact that quercetin also accumulates in mitochondria at high levels even at low concentrations (72, 179), potential toxic effects at high concentrations, especially in cancer cells, could also be mediated through HIB hydrolase.

In a molecular docking study, quercetin could be docked to the MEK1 pocket separate from but adjacent to the ATP binding site similar to that observed for PD318088, a highly selective MEK1 inhibitor that does not compete for ATP, in the crystal structure of the MEK1-PD318088 complex. The hydroxyl group at the $3^{\prime}$ position of the $\mathrm{C}$ ring of quercetin can make a critical hydrogen bond with the backbone amide group of Ser212 that would lock MEK1 into a catalytically inactive form by stabilizing the inactive conformation of the activation loop. The predicted binding mode of quercetin is also similar to that of PD318088. Binding of quercetin blocks the Raf/MEK/ERK/p90RSK pathway and leads to subsequent suppression of AP-1 and NF- $\kappa \mathrm{B}$ activity. Quercetin inhibited MEK1 activity more strongly than Raf1 activity, suggesting that MEK1 is the most potent molecular target of quercetin for suppressing neoplastic transformation (129).

Other possible direct targets have been suggested by using biotinylated quercetin as a tag to identify proteins with a strong binding affinity from a soluble cell extract. Some proteins that were identified based on this methodology are casein kinase II, ubiquitin-activating enzyme E1, heat shock protein 70 and 90, an ATPase, and two mitochondrial ATP synthase subunits (256). Quercetin may also interact with membrane proteins directly such as sugar transporters. Although there are no external docking sites on the sugar transporter GLUT1 for quercetin, within the inner vestibule, glutamate and lysine residues hydrogen-bond quercetin, completely inhibiting glucose transfer when bound (48). Quercetin also inhibited GLUT2, but not GLUT5 nor SGLT1 (128).
A potentially important molecular target of EGCG from green tea is the strong binding $\left(\mathrm{K}_{\mathrm{i}}=40 \mathrm{n} M\right)$ to the $67-\mathrm{kDa}$ laminin receptor, which is expressed on a variety of tumor cells, and the expression level of this protein strongly correlates with the risk of tumor invasion and metastasis (233). EGCG also strongly interacts with human leukocyte elastase (HLE) with an inhibition constant of $0.4 \mu M$. HLE is a serine protease found in the dense azurophil granules of polymorphonuclear leucocytes and possesses the ability to cleave elastin, the major component of elastic fibers that surround blood vessels, lung tissues, and ligaments. HLE may be activated on exposure to various cytokines and chemo-attractants, including TNF- $\alpha$, interleukin (IL)-8, C5a, and lipopolysaccharide. Abnormally elevated levels of HLE produced in the liver or deficiency in one of its natural inhibitors such as $\alpha_{1-}$ protease inhibitor cause severe permanent tissue damage. Hence, HLE has been linked to many inflammatory disorders (160). High blood concentrations of poly-morphonuclear HLE and IL-6 are indicators for the occurrence of multiple organ failures at the early stage of acute pancreatitis (104). More recently, acute exacerbation of idiopathic pulmonary fibrosis was associated with elevated serum neutrophil elastase and the role of these serine proteases is well acknowledged in the clinic (229). Inhibition of some others described that direct binding targets of EGCG such as matrix metalloproteinase (MMP)-2, thrombin, and cathepsin $\mathrm{G}$ are much weaker (210).

When considering the importance of the binding interactions, it would certainly be reasonable to assume that the tighter binding of a ligand, the more likely the effect would be relevant and evidenced in vivo. In addition, the effect on a cell would depend on the level of expression of the target protein. If, for example, the enzyme XOR was absent from a tumor cell line, then the cell would not be expected to respond to the effects of quercetin on uric acid metabolism since XOR is the key site of interaction for this effect (Fig. 2).

Controversial role of Nrf2 in cancer-direct and indirect regulation by quercetin. Quercetin also interacts directly with Nrf2. Nrf2 is a well-studied transcription factor that binds to the antioxidant response element (ARE) in promoters of many detoxifying or antioxidant enzyme genes in response to various xenobiotics and stresses $(5,107,246)$, and as a consequence, Nrf2 knockout mice are more susceptible to carcinogens (201). Nrf2 is also involved in protecting endothelial cells from glucose-induced oxidative stress (269) and in the expression of glyoxylase I, resulting in improved glucose homeostasis (270). Transcription of HO-1 is regulated through Nrf2 (123) via the ARE (5), and this responsive gene is often used as a marker of Nrf2 action. NQO1 (quinone reductase) was one of the first genes to be shown to contain an ARE and to require Nrf2 for transcription $(70,246)$. As part of the process of inducing NQO1, quercetin binds to the Nrf2 protein and increases its half-life four-fold (237). Chemically, quercetin can be oxidized to a quinone form via a semiquinone intermediate. The quinone form can then react with sulfhydryl groups to form a glutathione adduct (Fig. 6). This reaction can occur in cells (12), and consequently the 6- and 8-glutathionyl quercetin adducts are secreted into the medium. After consumption of quercetin in humans, glutathionyl quercetin adducts are found at low levels in urine, suggesting that the conjugation reaction can occur in vivo (101). The presence of ascorbate slows the 


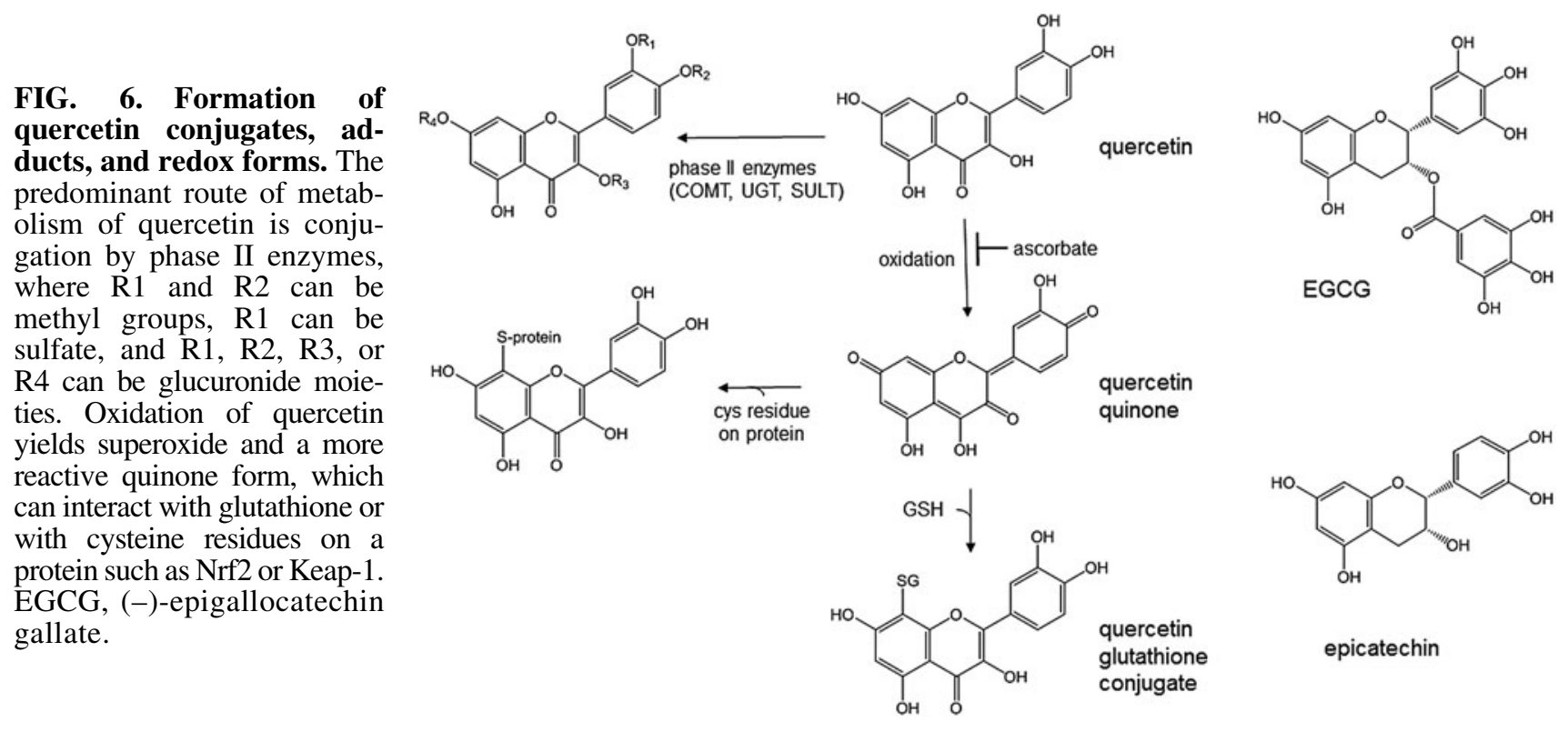

oxidation of quercetin and inhibits formation of the quinone forms (131), but, once formed, quercetin quinone reacts preferentially with thiol groups compared with ascorbate (23). The quinone form of quercetin is only a poor substrate for NQO1 and although NQO1 is induced by quercetin, NQO1 does not provide protection from the effects of quercetin quinone (22). Although these conjugation reactions clearly occur both in vitro and in vivo, the predominant reaction of quercetin is conjugation with methyl, glucuronosyl, or sulfate groups $(20,55,86)$, and as a result, these metabolites of quercetin dominate in urine $(101,166)$ and plasma $(53,166)$ (Figs. 1 and 6).

Keap-1 contains three crucial cysteine residues that play a role in the interaction with $\mathrm{Nrf} 2$, controlling its degradation via ubiquitin, and its response to oxidative stress. Both sulforaphane, a well-characterized inducer of NQO1 and HO-1, and oxidative stress stabilize Nrf2 by allowing it to escape Keap1-dependent degradation and activate genes by nuclear translocation and binding to the ARE. Cys151 is required for this process, and a post-translational modification of this residue is induced by oxidative stress (277). Since quercetin induces NQO1 and HO-1, it has been proposed that it could interact with Nrf2/Keap-1 to induce ARE-controlled enzymes (237), by forming protein adducts as shown in Figure 6. However, it is not known whether this occurs in cells. Quercetin binds to Nrf2 and stabilizes it, and it also binds directly to Keap-1, thus preventing its proteolytic degradation, and suggesting that the interaction of quercetin with the Cys151 is possible (237). However, some studies have suggested that quercetin does not interact with Nrf2 in endothelial cells (214), although we have data showing that quercetin is a potent HO-1 inducer in HUVECs (unpublished data). Further, stabilization of Nrf2 or of Keap-1 by interaction with cysteine residues requires catechol groups (225). Methylation of one of the hydroxyl residues of quercetin prevents the formation of thiol adducts (131), but since $4^{\prime}-O$ methylquercetin induces HO-1 in HepG2 cells (272), this suggests that interaction of the catechol group with thiol residues on Keap-1 or Nrf2 is not the only mechanism of induction of ARE-controlled genes by flavonoids. When treated with $20 \mu M$ quercetin, GSH concentration in HAEC transiently dropped by $20 \%$ and returned to baseline within $18 \mathrm{~h}$. Since GSSG also decreased, this suggests that these changes were due to consumption of glutathione rather than thiol oxidation, and in support of this, quercetin glutathione conjugates were exported into the medium (132).

A substantial literature documents the chemopreventive effect of Nrf2 activators (268), particularly those that are naturally occurring. Nrf2 activators, such as sulforaphane, curcumin, and dithiolethiones (Oltipraz), have undergone clinical trials (142). However, some recent research implicating Nrf2 in tumor cell proliferation is causing controversy. Studies in breast cancer cells revealed that $\mathrm{Nrf} 2$ regulated the expression of growth factors, transmembrane receptors, kinases, and transcription regulators under hypoxia through the GSH signal that impinges on cell proliferation $(204,232)$. The hyper-activated Nrf 2 can contribute to overexpression of target genes, leading to cancer cell survival and proliferation. In addition, Nrf2 can aid cancer cells in resisting chemotherapy and radiotherapy (268). Nrf2 overexpression enhanced resistance to chemotherapeutic drugs, such as cisplatin, doxorubicin, and etoposide, in cancer cells (258). In addition, Nrf 2 silencing through RNA interference inhibited tumor growth and enhanced the efficacy of chemotherapy in nonsmall-cell lung carcinoma cells (222). The aberrant activation of Nrf2 was attributed to the radio resistance in NSCLC cells (221) and linked to upregulation of drug efflux pumps, such as ABCG2, which enhances the resistance to anticancer drugs in lung epithelial cells (223). Increased expression of the ABC transporters would also blunt interactions of polyphenols with cellular targets due to increased elimination of intracellularly formed metabolites.

In contrast with normal cells, Nrf2 protein constitutive upregulation in many tumors is due to somatic mutations in the Keap1 or Nrf2 genes (98). It has also been suggested that in certain settings Nrf2 augments purine nucleotide synthesis, thus supporting tissue hypertrophy. In human lung A549 cells constitutively overexpressing Nrf2 due to harboring of mutant Keap1, upregulation of Nrf2 led to increased utilization of glutamine by increasing GSH synthesis as a consequence of glutamate-cysteine ligase induction and 
increased decarboxylation of malate as a consequence of malic enzyme 1 induction (161). This change in cellular metabolism required both loss of Nrf2 repression by Keap1 and costimulation via the PI3K-Akt pathway as opposed to induction of antioxidant and detoxification genes, which requires only inhibition of Keap1. So far, a role for quercetin has only been described with regard to the cytoprotective role of Nrf2.

Recent work has further complicated the Nrf2 activation story as the acetylation-deacetylation status of Nrf2 was also found to define its nuclear translocation, its ability to promote transcription, and its egress from the nucleus to terminate its transcriptional activity (112). Specifically, SIRT1, which belongs to the family of $\mathrm{NAD}^{+}$-dependent deacetylases, was shown to decrease acetylation of $\mathrm{Nrf2}$, as well as Nrf2dependent transcription (103). Quercetin could affect SIRT1 through inhibition of $\mathrm{NAD}^{+}$-consuming enzymes such as CD38 and PARP $(69,81)$ and could, therefore, have an indirect effect on Nrf2 acetylation status, although this mechanism of action has not been explored.

On the basis of this evidence, there seems to be a dual role of Nrf2 in carcinogenesis: beneficial in the early stages where activation of the Nrf2 pathway leads to activation of cytoprotective genes and thus generation of antioxidant machinery that removes ROS, reactive aldehydes such as 4hydroxynonenal, and xenobiotics from the cells; but detrimental in later stages of cancer by increasing resistance to conventional radio- and/or chemotherapy. Such effects are relevant to all stages of cancer progression, as shown in Figure 7, however to different extents.

\section{Multimodal effects of quercetin and epicatechin on HepG2 cells and hepatocytes affecting cellular homeostasis.}

The effect of quercetin on HepG2 cells is very concentration dependent, and there is abundant evidence to show that at $>30 \mu M$, the dominant effect is on the cell cycle progression, apoptosis, and cell death. At these concentrations, quercetin decreased cyclin D1 protein and induced G1 phase arrest (283), increased gene expression of the tumor suppressor p16 (278), and of Cdk inhibitors p21 and p27, whose loss can mediate a drug-resistance phenotype, increased tumor suppressor p53 (165), activated JNK and ERK signaling pathways (249), decreased survivin (BIRC5), an inhibitor of apoptosis that attenuates caspase activation, and Bcl-2 protein levels, increased caspase-3/caspase-9 activity (235), downregulated expression of PI3K, PKC, and COX-2, and enhanced the expression of B-cell lymphoma-2-like protein 4 (Bax) (150). At similar concentrations $(50 \mu M$ for $48 \mathrm{~h})$, quercetin downregulated the Ras GTPase-activating protein and $\beta$-tubulin and these effects were correlated with reduced cell migration ability. When $10 \mu M$ was directly compared with $100 \mu M$, only the higher concentration of quercetin induced significant apoptosis (119), and several studies report that quercetin at $<20 \mu M$ has only a minimal effect on HepG2 cell death. Further, the effect of quercetin on caspase- 3 activity was maximal at $50 \mu M$ in HepG2 and declined at higher concentrations whereas this coincided with mitochondrial Bax activity (87). Low doses of quercetin $(0.1-1 \mu M)$ increased $\mathrm{Cu} / \mathrm{Zn}$ superoxide dismutase and glutathione peroxidase mRNA in tert-butyl hydroperoxide-treated HepG2 cells (6). High concentration effects have led to claims that quercetin can inhibit the growth of cancer cells and, hence, could act as a chemopreventive agent.

The effect of high concentrations of quercetin on cell death is less pronounced in primary human hepatocytes. Quercetin as high as $100 \mu M$ did not affect the viability of human hepatocytes as assessed by lactate dehydrogenase release into culture medium, and had no effect on CYP2E1 nor intracellular GSH concentration, and this high concentration actually protected cells from ethanol-induced toxicity through induction of HO-1 via the MAPK/Nrf2 pathways $(273,274)$.

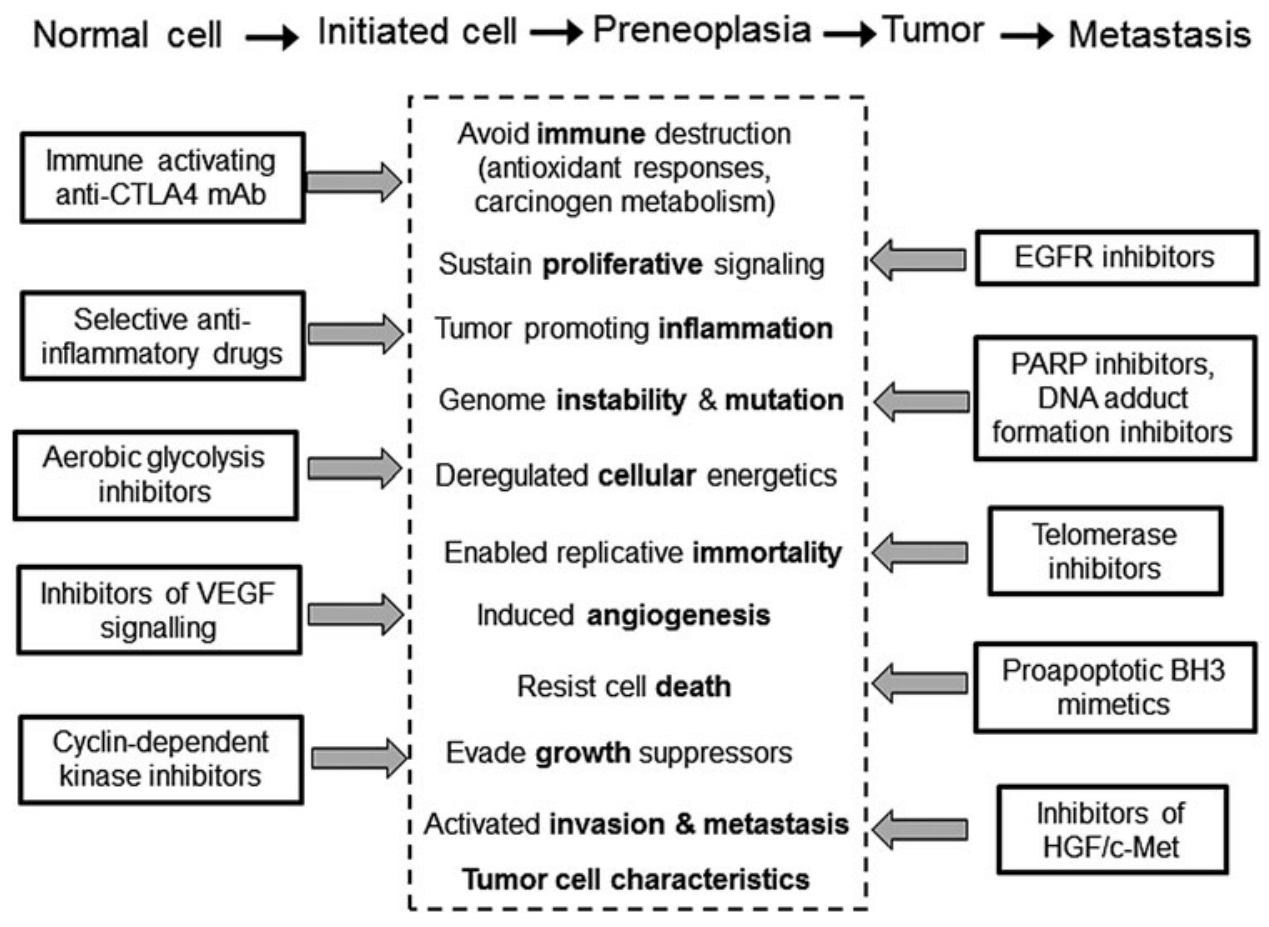

FIG. 7. The defining characteristics of cancer cells. Adapted from Ref. (95). 
These reported differences between the cancer phenotype of immortalized cells and primary isolated cells can cloud judgement, since the potential molecular targets of a flavonoid are linked to the differential metabolic signature of the cells and also their tumor background.

Quercetin at $>25 \mu M$ also lowered intracellular FASN mRNA and activity and overall modulated fatty acid synthesis (279). Oleic acid induced lipid droplet formation, increased triglycerides, the inflammatory cytokines TNF- $\alpha$ and IL-8, and increased insulin resistance as apparent by inhibition of insulin-stimulated glucose uptake. Quercetin at $10 \mu M$ protected against oleic acid-induced hepatic steatosis as shown by decreased triglyceride content, increased insulinmediated glucose uptake, increased intracellular glutathione, decreased TNF- $\alpha$ and IL-8, increased total superoxide dismutase activity, catalase and glutathione peroxidase activities, increased albumin and urea, and decreased alanine aminotransferase activity (247).

As has been reported in several systems, quercetin is a potent competitive inhibitor of GLUT1 (147) whereas it was also reported to inhibit the uptake of glucose and of (nonmetabolized) deoxy-D-glucose in HepG2 cells, but over $12 \mathrm{~h}$, increased mRNA expression of the main GLUTs GLUT1 and of GLUT9 (116), presumably as a response to the acute inhibition. Given the differential expression of GLUTs between cancer cell lines, normal tissues, and in cancer, this activity of quercetin may be of importance in potentiating cellular reprogramming and induction of apoptosis of cancer cells. Treatment of HepG2 cells with quercetin $(50 \mu M$ for $48 \mathrm{~h})$ led to $\sim 70$ protein changes, notably involved in metabolism; cytoplasmic malate dehydrogenase and succinate dehydrogenase were substantially downregulated, whereas FASN, L-lactate dehydrogenase A chain, $\alpha$-enolase, glyceraldenhyde3-phosphate dehydrogenase, and phophoglycerate kinase were all upregulated (284).

In rat hepatocytes, fatty acid synthesis was reduced dose dependently by quercetin, between 2.5 and $50 \mu M$ (84), in broad agreement with the effect described earlier (279) on HepG2 cells. Cholesterol synthesis was unaffected in hepatocytes. Quercetin at $25 \mu M$ decreased ACC and diacylglycerol acyltransferase activities, but it did not affect FASN nor HMG-CoA reductase activities (84). This implies that although the overall effect of quercetin on rat hepatocytes is to decrease fatty acid synthesis, the mechanism may differ from that observed in human HepG2 cells, possibly because of the species difference in cell line origin. The product of ACC is malonyl-CoA, which implies that quercetin would decrease malonyl-CoA levels through decreased ACC activity. Incorporation of labeled acetate into VLDL-triglyceride was reduced by $36 \%$ in the presence of quercetin, and quercetin was, therefore, proposed to decrease both de novo fatty acid synthesis and triglyceride synthesis in rat hepatocytes (84).

High glucose decreased tyrosine-phosphorylated and total levels of IR, IRS-1 and -2, inactivated AMPK, and the PI3K/ Akt pathway, decreased GLUT2, increased PEPCK, and diminished glucose uptake in HepG2 cells. Pre-treatment with epicatechin $(10 \mu M)$ attenuated or prevented these changes, suggesting improved insulin sensitivity and delay of potential hepatic dysfunction (44). In the same cell line, high glucose increases phosphorylation of IRS-1, leading to lowered insulin-stimulated phosphorylation of Akt, and this effect is partially blocked by EGCG. These effects are mediated via
EGCG-activated AMPK (139). In comparison and under normal glucose conditions, quercetin at the lowest concentration tested $(10 \mu M)$ increased the phospho-Akt:Akt and phospho-ERK:ERK ratios, but notably this effect declined at higher concentrations and was reversed by $100 \mu M$ (87).

Phospho-Nrf2 increased after treatment of HepG2 cells with quercetin up to $10 \mu M$, then decreased to below control values at $50 \mu M$, as did the ratio of nuclear to cytosolic Nrf2 (88). Bell-shaped responses are commonly evidenced for Nrf2 activators and, although the reason behind this is not known, other post-transcriptional modifications and secondary interactions with deacetylases are believed to be involved (103). Similarly, quercetin at high, but not low $(<10 \mu M)$, concentrations induced CYP1A1 mRNA and activity in HepG2 cells (249) but neither CYP2E1 protein nor activity (273) was affected by $100 \mu M$ treatment with quercetin. Using hepatocytes from two donors, quercetin at $>80 \mu M$ did not induce the conjugating enzyme UGT1A1, the efflux transporters $\mathrm{ABCB} 1$ or $\mathrm{ABCC} 2$, nor the cytochrome $\mathrm{P} 450 \mathrm{~s}$, CYP1A2, CYP2B6, and CYP3A4, whereas quercetin induced the expression of UGT1A1 and CYP1A2 in HepG2 cells (134). In human hepatocytes from one donor, quercetin at $10 \mu M$ produced no change in the conjugating enzymes UGT1A1 and SULT2A1, the transporters ABCG5 and ABCC 3 , nor in $\mathrm{HNF} 4 \alpha$, but at 50 and $250 \mu M$ some of these genes were downregulated (134). At 5-25 $\mu M$, quercetin induced the mRNA expression of several mitochondrial biogenesis activators ( $\mathrm{PGC} 1 \alpha$, nuclear respiratory factor-1, and mitochondrial transcription factor $\mathrm{A}$ ), mitochondrial DNA, and COX IV protein in HepG2 cells, through a mechanism involving HO-1 (203). At $100 \mu M$, the induction of $\mathrm{HO}-1$ by quercetin was accompanied by increased $\mathrm{Nrf} 2$ in the nucleus and this increase was abolished by MAPK inhibitors (274).

At high concentrations of quercetin, pregnane $\mathrm{X}$ receptor, constitutive androstane receptor, and the aryl hydrocarbon receptor were activated in HepG2 cells (134). Quercetin at 10 and $50 \mu M$ did not change the mRNA levels of $\beta$-catenin, cfos, c-jun, GADD45, IL-1 $\beta$, IL-1R, LBP, p21CIP1, and STAT3 in human hepatocytes, but quercetin at $10 \mu M$ (but not at $50 \mu M)$ modulated c-fos and LBP in HepaRG cells. There appeared to be no changes in transcriptomic profile in human hepatocytes by 10 and $50 \mu M$ quercetin, but only one donor was used (250).

In human hepatocytes, quercetin $(20 \mu M)$ protected against formation of ${ }^{14} \mathrm{C}$-labeled PhIP-DNA adducts, but with substantial inter-individual variation in the extent of protection in the four donors tested. In HepG2 cells, quercetin also protected and the effect was dose dependent up to $20 \mu M$. The number of PhIP-DNA adducts was dose dependent over a wide range of $\mathrm{PhIP}$ concentrations, and there were $\sim 30$-fold more adducts in hepatocytes compared with HepG2 cells, due at least, in part, to higher CYP1A2 activity in hepatocytes (Fig. 2) (14). In HepG2 cells, quercetin at low concentrations (0.1 $\mu M$ and above) inhibited activity of cytochrome P450, but it did not induce glutathione S-transferase, CYP1A1, cfos, heat shock protein 70, tumor suppressor p53, transcription factor NF- $\kappa \mathrm{B}$ nor DNA damage (171), and at $10 \mu M$, did not increase NF- $\kappa \mathrm{B}$ binding activity nor DNA strand breakage, but protected against hydrogen peroxide-induced increase in NF- $\kappa \mathrm{B}$ activity and DNA strand breakage (170). $\mathrm{NF}-\kappa \mathrm{B}$ can be glutathionylated (186), and quercetin 
transiently decreased glutathione concentration in human aortic endothelial cells (132).

\section{Interaction of quercetin with intestinal tissue and cells}

The intestine is the primary site of interaction with orally consumed flavonoids. The concentration in the gut lumen to which the enterocytes are exposed can reach $\mathrm{m} M$ levels (261). Green tea catechins are present in their active forms, such as EGCG and epicatechin, but many other flavonoids such as quercetin are glycosylated (198), and experiments in vivo and in vitro need to be designed to take these factors into consideration (Fig. 1). When treated with quercetin in the aglycone form, some effects on the intestine are comparable both in vitro and in vivo. For example, quercetin enhanced barrier function in rat ileum and distal colon, and it also attenuated TNF- $\alpha$ - and interferon- $\gamma$-induced damage to HT29/B6 cell monolayers (7). Using Caco-2 monolayers, the mechanism may be through the assembly of the tight junction proteins, $\mathrm{ZO}-2$, occludin, and claudin-1 by inhibiting $\mathrm{PKC} \delta$ (231). When a low dose of quercetin was given to BALB/c mice, changes in the small intestine gene expression involved downregulation of genes related to calcium signaling and lipid metabolism, and upregulation of genes related to ribosomal protein and xenobiotic metabolism (176). In human colonic LS180 cells and Caco-2 cells, quercetin suppressed endoplasmic reticulum stress caused by calcium dynamics dysregulation by the inhibition of PI3K (175). Quercetin inhibited TNF-induced interferon- $\gamma$-inducible protein 10 (IP-10) and macrophage inflammatory protein 2 (MIP-2) proinflammatory gene expression in murine small intestinal epithelial Mode-K cells. In comparison, quercetin given orally to heterozygous TNF $\delta$ ARE/WT mice, a model of experimental ileitis, inhibited IP-10 and MIP-2 gene expression in ileal epithelial cells without affecting tissue pathology (208).

In C57BL/6 mice fed quercetin, transcriptomic analysis showed that genes involved in fatty acid metabolism and glutathione metabolism were modulated in the small intestine (172). In the distal colon of rats fed quercetin chronically, transcriptomic analysis showed that the MAPK pathway was downregulated, tumor suppressor genes, including phosphatase and tensin homolog (PTEN), Tp53, and Msh2, cell cycle inhibitors, including MUTYH, a DNA glycosylase involved in DNA repair, and genes involved in phase I and II metabolism, including the flavin-containing dimethylaniline monooxygenase 5, epoxide hydrolase, and glutathione peroxidase, were upregulated, together with $\operatorname{PPAR} \alpha$ target genes, and enhanced expression of genes involved in mitochondrial fatty acid degradation. Transcriptome changes were poorly correlated with the proteome, but both indicated altered energy metabolism, and showed that quercetin evoked changes contrary to those observed in colorectal carcinogenesis. In vivo, tumor-protective mechanisms and a shift in energy production pathways indicated decreased cytoplasmic glycolysis and increased mitochondrial fatty acid degradation (59). In contrast, when Caco-2 cells were treated with quercetin (stabilized by ascorbate against degradation; see Fig. 6), genes involved in cell survival and proliferation were affected, genes involved in tumor suppression were downregulated, and oncogenes were upregulated (58). There are many studies on the interaction of quercetin with HT29 cells, but, in general, quercetin is much more toxic to proliferating cancer cells during replication compared with cells post-differentiation when the culture model is more representative of the established tissue phenotypic functionalities (3).

\section{Effect of flavonoids on pancreas and pancreatic cells}

Effect of quercetin on pancreas and pancreatic cells in vivo. Numerous in vitro studies on quercetin and pancreatic cells have been reported, and some of these have also been supported by studies on animal models in vivo. Quercetin given orally significantly attenuated the severity of cerulein-induced acute pancreatitis in mice as shown by reduction in pancreatic weight, pro-inflammatory cytokines, myeloperoxidase activity, increased anti-inflammatory cytokine IL-10, and suppression of pancreatic edema (34). Streptozotocin induces pancreatic damage via uptake into $\beta$ cells via GLUT2 (67). Streptozotocin-treated rats can be a model for hyperglycemia, type 1 diabetes, or type 2 diabetes depending on the dose used (67); in the type 1 model, quercetin protected and preserved pancreatic $\beta$ cell architecture, attenuated the increase in plasma glucose (2), and prevented islet cell degeneration (45). In rats fed a high-fat diet to induce hypertriglyceridemia with acute pancreatitis induced by an intraperitoneal injection of cerulein, quercetin reduced plasma amylase, attenuated pancreatic histopathological damage, reduced the mRNA and protein expression of inflammatory mediators NF- $\kappa \mathrm{B}$, IL- $1 \beta$, IL- 6 , and TNF- $\alpha$, and downregulated gene and protein expression levels of IRE $1 \alpha$, sXBP1, C/EBP $\alpha$, and $\mathrm{C} / \mathrm{EBP} \beta$ (281).

Quercetin reduced serum insulin and leptin, blocked islet hyperplasia in fructose-fed rats, a model of type 2 diabetes, and also prevented fructose-induced $\beta$ cell proliferation and insulin hypersecretion in INS-1 $\beta$-cells (133). Quercetin counteracted the cholesterol-induced activation of the NF- $\kappa \mathrm{B}$ pathway in the pancreas of rats fed high cholesterol, normalizing the expression of pro-inflammatory cytokines (33). Dietary supplementation of quercetin attenuated the growth of transplanted pancreatic tumor xenografts in a nude mouse model (10). Many of these studies indicate a protective effect of quercetin against pancreatic cancer development, but the doses used in these studies were mostly pharmacological rather than dietary. In a study on 76 patients suffering acute pancreatitis, pre-operative treatment with quercetin substantially reduced the organ dysfunction rate as well as polyorgan insufficiency (50).

Effect of quercetin on pancreas and pancreatic cells in vitro. There is a scarcity of human cell lines available for studying pancreatic $\beta$ cells and the most commonly used cell line, INS-1, is derived from mice. In this cell line and in isolated pancreatic islets from rats, quercetin stimulated insulin secretion by increasing $\mathrm{Ca}^{2+}$ influx through an interaction with L-type $\mathrm{Ca}^{2+}$ channels (15). Quercetin induces the microRNA let-7c in cells, and in vivo, xenotransplantation of PDAC cells with an intravenous injection of let-7c decreased tumor mass in the fertilized chick egg model (180). Quercetin downregulated cellular FLICE-like inhibitory protein, whose overexpression was able to rescue pancreatic cancer cells from TNF-related apoptosisinducing ligand/quercetin-induced apoptosis (120). In Min6 cells, quercetin counteracted cholesterol-induced activation of 
the NF- $\kappa \mathrm{B}$ pathway, normalized expression of pro-inflammatory cytokines (33), and inhibited the growth of two human pancreatic cancer cell lines by inducting apoptosis (10).

Interaction of epicatechin and green tea with pancreas and pancreatic cells. Epicatechin protected INS-1E pancreatic $\beta$ cells from tert-butylhydroperoxide-induced damage, by preventing increased ROS, carbonyl groups, p-JNK expression, and cell death, and recovering insulin secretion (148). A combination of sulforaphane, quercetin, and green tea catechins inhibited PDAC progression by inducing the microRNA let7-a and inhibiting the proto-oncogene K-ras in two established, one primary PDAC cell line, and in nonmalignant pancreatic ductal cells (11). In premalignant and malignant K-ras-activated PDAC cells, epicatechin decreased proliferation, GTP-bound Ras protein, Akt phosphorylation, and NF- $\kappa$ B transcriptional activity, but it had no observable effect on normal pancreatic ductal epithelial cells. Further, oral administration of epicatechin-containing cocoa polyphenols inhibited the growth of K-ras-PDAC cell-originated tumors in a xenograft mouse model (219). In another in vitro study in human PDAC cells, the two minor green tea catechins, epicatechin gallate and catechin gallate, had much stronger anti-proliferative and anti-inflammatory effects, including inhibition of NF- $\kappa \mathrm{B}$, IL-8, and uPA, than EGCG (126). Epicatechin inhibited IL-1 $\beta$-induced inducible nitric oxide synthase (iNOS) expression by downregulating NF- $\kappa \mathrm{B}$ activation, and protecting RINm5F $\beta$ cells and islets from the effects of IL-1 $\beta$ (122). In streptozotocin-treated rats, epicatechin protected from hyperglycemia and weight loss, and it preserved islet morphology and insulin release (121).

\section{Effect of flavonoids on breast cancer tissue and cells}

Effect of quercetin on breast cancer tissues and cells. The effect of quercetin on various cell models for breast cancer has been extensively studied. Most in vitro studies have been performed on estrogen receptor (ER)positive MCF-7 and on ER-negative MDA-MB-231 cells, and a comparison between the two cell lines provides information on the role of the ER. Quercetin inhibited the growth of MCF-7 cells, promoted apoptosis by inducing G0/G1 phase arrest, and regulated the mRNA expression of survivin (56). At a very high concentration, quercetin at $150 \mu M$ induced apoptosis by direct activation of the caspase cascade through the mitochondrial pathway (40). Quercetin induced partial co-localization of phospho-Akt and phospho-AMPK in the nucleus of MCF-7 breast cancer cells (130). Quercetin3-O-glucuronide, one of the main human phase II metabolites of quercetin in blood, showed $\mathrm{ER} \alpha$ - and $\operatorname{ER} \beta$-dependent estrogenic activity in MCF-7 cells (209). Quercetin can reverse tamoxifen resistance in breast cancer MCF-7Ca/TAM-R cells, involving upregulation of $\mathrm{ER} \alpha$ and downregulation of Her-2 (receptor tyrosine-protein kinase erbB-2), an epidermal growth factor receptor and oncogene target in breast cancer (252). In MDA-MB-453 cells, high concentrations of quercetin $(100 \mu M)$ increased the number of sub-G1 phase cells, increased apoptosis, increased Bax expression, decreased Bcl-2 expression, and increased cleaved caspase-3 and poly[ADP-ribose]polymerase 1 expression (39). Quercetin $(100 \mu M)$ showed cytotoxicity in MCF-7 cells, but not in MDA-MB-231, by suppressing expression of cyclin D1, p21, Twist, and phospho-p38MAPK, which induced apoptosis in MCF-7 cells (202). Quercetin-3-O-glucuronide at a very low concentration $(0.1 \mu M)$ suppressed invasion of MDA-MB-231 breast cancer cells and MMP-9 induction, by controlling $\beta 2$-adrenergic signaling (271). Quercetin with vitamin $C$ decreased Nrf2 mRNA and protein levels and of endogenous ROS in MDA-MB 231, MDA-MB 468, A549, and MCF-7 breast cancer cells (164). Quercetin and EGCG concentration dependently inhibited deoxy-D-glucose uptake by both MCF-7 and MDA-MB-231 cells, and both compounds blocked lactate production by MCF-7 cells (163). Quercetin can also increase the sensitivity of breast cancer cells to doxorubicin through downregulation of phospho-Akt expression arising from increased expression of PTEN; this protein functions as a tumor suppressor by negatively regulating the Akt/Protein Kinase B signaling pathway (135).

Quercetin has been studied in animal models for antibreast cancer activity. After 3 weeks, it decreased tumor growth, limited oncocyte proliferation, promoted tumor necrosis in female BALB/c nude mice injected with MCF-7 cells into the mammary fat, inhibited tumor calcineurin (calcium- and calmodulin-dependent serine/threonine protein phosphatase) activities, and inhibited angiogenesis. In vitro, it also inhibited calcineurin activity (280). Quercetin dose dependently decreased tumor number and volume in a transgenic C3(1)/SV40 Tag breast cancer mouse model of human breast cancer, and at the lowest dose of $0.2 \%$ of diet, 31 genes were downregulated and 9 genes were upregulated more than twofold (227). Quercetin improved the therapeutic index of the anthracycline antibiotic doxorubicin by its opposing effects on HIF- $1 \alpha$ in $4 \mathrm{~T} 1$ tumor cells and in murine normal spleen cells evaluated in BALB/c mice with 4T1 breast cancer. It suppressed intratumoral HIF- $1 \alpha$ in a hypoxia-dependent manner in tumor cells, but in contrast increased its accumulation in normal cells (62). However, a study has claimed that quercetin does not confer protection against breast cancer, does not inhibit endogenous estrogen $17 \beta$-estradiol $\mathrm{E}(2)$-induced oxidant stress, and may even exacerbate breast carcinogenesis in $\mathrm{E}(2)$-treated female $\mathrm{ACI}$ rats (224).

Effect of epicatechin and green tea on breast cancer tissue and cells. MMPs play an important role in tissue reconstruction near proliferating cells of malignant neoplasms during cancer metastasis, whereas, significantly, low levels of tissue inhibitor of matrix metalloproteinase-3 (TIMP-3) protein expression in breast cancer have been reported to be correlated with an aggressive cancer phenotype. EGCG at $20 \mu M$ was reported to mediate epigenetic activation of TIMP-3 levels, resulting in suppression of invasiveness and gelatinolytic activity of MMP-2 and MMP-9 in MDA-MB231 and MCF-7 breast cancer cells $(54,173)$. Although both EGCG and EGC at $30 \mu M$ inhibited heregulin-1-induced migration and invasion of MCF-7 cells, EGCG action was shown to be due to downregulation of the ErbB2/ErbB3/ $\mathrm{PI} 3 \mathrm{~K} / \mathrm{Akt}$ signaling, whereas (-)-epigallocatechin (EGC) exerted these effects through pathways involved in the inhibition of ErbB2/ErbB3 but not Akt (127). These data suggest that EGCG and EGC reduce MMP-9 expression through different signaling pathways and are in agreement with an indirect mechanism of action on MMPs as direct binding of EGCG to MMP-2 was very weak (210). 
Inhibition of $\mathrm{NF}-\kappa \mathrm{B}$ activity is believed to disrupt the metastatic potential of mammary epithelial cells in a model system through regulation of genes linked to cell motility, invasion, and metastasis, including the genes encoding MMPs. The inhibitory effect of epicatechin at $10 \mu \mathrm{M}$ on invasion of cancer cells into embryonic stem cell-derived, vascularized tissues was attributed to downregulation of MMP-9 expression (91). Finally, the inhibitory activity of EGCG in cancer progression and invasion was also seen in mouse mammary cancer cells through activation of Forkhead box $\mathrm{O}$ transcription factor, the major regulator of $\mathrm{ER} \alpha$ signaling. This led to repression of epithelial-to-mesenchymal transformation, halting the generation of the mesenchymal phenotype that has highly invasive characteristics, causing the primary cancer to emigrate (17). The presence of $E R \alpha$ is considered a good prognostic factor and correlates with a higher degree of cancer differentiation (47), whereas recent research has shown that high levels of MMP-9 were negatively correlated with ER (267).

\section{Synergistic Effects of Polyphenols in Chemotherapy}

Green tea catechins have been tested as an adjuvant in chemotherapy. Some studies have reported beneficial effects of EGCG or green tea extract with anticancer drugs, such as bleomycin in cervical cancer cells, cisplatin in vitro in various cancer cell lines and in mouse models in vivo, tamoxifen in human breast cancer cells in vitro, and negative effects with bortezomib, diminishing its antitumor effects in CWR22 xenograft-bearing breast cancer mice (30). The positive reported outcomes of green tea catechins and mainly of EGCG were related to induction of apoptosis and ROS, caspase activity, and in the case of cisplatin reduction of drug resistance and amelioration of cisplatin treatment side effects. EGCG was found to inhibit the transport activity of P-glycoprotein (ABCB1) and may be an effective P-glycoprotein modulator, one of the main transporters conferring drug resistance, while it also increased chemotherapy drug accumulation in multidrug-resistant cells (259).

However, such interactions could also unexpectedly affect the pharmacokinetics and bioavailability of coadministered chemotherapeutic agents in cancer patients and, as such, influence its efficacy and toxicity profile. A total of 80 clinical trials involving both green tea and cancer are listed in clinicalTrials.gov focusing on treatment, prevention, or risk reduction of reoccurrence of breast, prostate, colon, and lung cancer and many other conditions. Interestingly, a study in progress focuses on patients with premalignant lesions of the head and neck after treatment with erlotinib and EGCG. In in vitro work treatment of squamous cell carcinoma of the head and neck cell lines with erlotinib activated p53. This activation had a critical role in the synergistic growth inhibition by erlotinib and EGCG via the $\mathrm{NF}-\kappa \mathrm{B}$ signaling pathway (8). Erlotinib is a tyrosine kinase inhibitor that targets the receptor of epidermal growth factor. However, when used as a "monotherapy," it is known to increase vascular endothelial growth factor production by mechanisms involving CYP1A2, oxidative stress, and MEK1/2, thereby possibly favoring angiogenesis and growth of early hepatocellular tumors, and so limiting the therapeutic and chemopreventive effects of erlotinib
(206). A previous clinical trial showed a significant reduction in serum levels of prostate-specific antigen, hepatocyte growth factor, and vascular endothelial growth factor in men with prostate cancer after brief treatment with EGCG (154). In that light, the potential of EGCG to restrict such adverse effects of erlotinib through combined mechanisms remains to be seen.

In comparison, a total of eight studies are listed in clinicalTrials.gov involving quercetin in patients undergoing chemotherapy. In an ongoing study, for example, quercetin is explored for its potential to activate AMPK and overcome the fatigue side effects of sunitinib in patients with kidney cancer.

Although studies in healthy volunteers are usually conducted in a randomized, placebo-controlled, cross-over, or parallel design depending on the power of the study, clinical trials on cancer patients are mainly open labeled and singlegroup assignment, the endpoint being closely relevant to the drug treatment and cancer condition. Although these parameters are dictated by the ethical aspects of the study when dealing with patients, nonetheless, they can compromise the significance of the effects.

\section{Conclusions}

The interplay between oxygen availability and metabolism is key to a detailed understanding of how a tissue responds to hypoxia, especially in the case of cancer. The orchestrated activities of related kinase cascades, nuclear factors, and transcriptional modifications define the fate of the cell whether activating antioxidant responses or entering the apoptotic phase. Phytochemicals and flavonoids, as such, are believed to have a role to play in maintaining the overall cellular redox balance, and evidence points to a beneficial impact through interactions with specific high-affinity molecular targets as described here. However, natural compounds cannot be seen as a panacea, especially when taking into account differences between biological settings in health and disease.

Given that quercetin, for example, is known to partly accumulate in mitochondria (72), there is no doubt that in compromised, damaged mitochondria with lower capacity for stress responses, potential bioactivities will be magnified. Although quercetin aglycone plasma levels are usually low, due to its extensive metabolism, circulating glucuronides, sulfates, and O-methylated forms of quercetin may also produce beneficial effects as both the flavonoid and the $\mathrm{O}$ methylated flavonoid glucuronides may be de-conjugated by $\beta$-glucuronidases present in human tissues, in particular at the inflammatory sites $(106,113,191)$. However, taking into account the fact that solid tumors usually have decreased blood flow and that the metabolic modifications in vivo to the quercetin structure restrict its bioavailability, together with the inhomogeneous nature of cancers, the window for clinical efficacy of quercetin in cancer seems to be narrow in the established tumor, not excluding possible beneficial effects on chemoprevention at the initial stages of cancer progression. Although green tea catechins have been widely studied for cancer chemoprevention, and epidemiology strongly supports a beneficial role, research outcomes summarized here highlight key activities in reversing root-and-cause inflammatory excursions and, therefore, 
improving the overall clinical symptoms of cancer. Intraperson variability and cancer type are also expected to impact the beneficial clinical potential of polyphenols considering changes in phase II detoxifying enzymes affecting hepatobiliary excretion.

Nonetheless, synergistic interactions of flavonoids with standard chemotherapeutics are becoming the objective of further research in the area as both in vitro and in vivo studies have indicated that both quercetin and EGCG could enhance their bioavailability and accumulation while sensitizing cancer cells to their actions and reversing side effects. From a clinical perspective, this would allow potential dose reduction of drug toxicity and help prevent severe side effects in the clinic, while providing another avenue to maximize outcomes at minimal cost.

\section{Acknowledgment}

The work was supported by a European Research Council Advanced Grant "POLYTRUE?”' (322467).

\section{Author Disclosure Statement}

No competing financial interests exist.

\section{References}

1. Actis-Goretta L, Leveques A, Giuffrida F, RomanovMichailidis F, Viton F, Barron D, Duenas-Paton M, Gonzalez-Manzano S, Santos-Buelga C, Williamson G, and Dionisi F. Elucidation of (-)-epicatechin metabolites after ingestion of chocolate by healthy humans. Free Radic Biol Med 53: 787-795, 2012.

2. Adewole SO, Caxton-Martins EA, and Ojewole JA. Protective effect of quercetin on the morphology of pancreatic beta-cells of streptozotocin-treated diabetic rats. Afr J Tradit Complement Altern Med 4: 64-74, 2006.

3. Agullo G, Gamet L, Besson C, Demigne C, and Remesy C. Quercetin exerts a preferential cytotoxic effect on active dividing colon carcinoma HT29 and caco-2 cells. Cancer Lett 87: 55-63, 1994.

4. Ahlin G, Hilgendorf C, Karlsson J, Szigyarto CA, Uhlen M, and Artursson P. Endogenous gene and protein expression of drug-transporting proteins in cell lines routinely used in drug discovery programs. Drug Metab Dispos 37: 2275-2283, 2009.

5. Alam J, Stewart D, Touchard C, Boinapally S, Choi AMK, and Cook JL. Nrf2, a Cap'n'Collar transcription factor, regulates induction of the heme oxygenase-1 gene. J Biol Chem 274: 26071-26078, 1999.

6. Alia M, Ramos S, Mateos R, Granado-Serrano AB, Bravo L, and Goya L. Quercetin protects human hepatoma HepG2 against oxidative stress induced by tert-butyl hydroperoxide. Toxicol Appl Pharmacol 212: 110-118, 2006.

7. Amasheh M, Luettig J, Amasheh S, Zeitz M, Fromm M, and Schulzke JD. Effects of quercetin studied in colonic HT-29/B6 cells and rat intestine in vitro. Ann N Y Acad Sci 1258: 100-107, 2012.

8. Amin AR, Khuri FR, Chen ZG, and Shin DM. Synergistic growth inhibition of squamous cell carcinoma of the head and neck by erlotinib and epigallocatechin-3-gallate: the role of p53-dependent inhibition of nuclear factor-kappaB. Cancer Prev Res (Phila) 2: 538-545, 2009.
9. An G, Wang X, and Morris ME. Flavonoids are inhibitors of human organic anion transporter 1 (OAT1)-mediated transport. Drug Metab Dispos 42: 1357-1366, 2014.

10. Angst E, Park JL, Moro A, Lu QY, Lu X, Li G, King J, Chen M, Reber HA, Go VL, Eibl G, and Hines OJ. The flavonoid quercetin inhibits pancreatic cancer growth in vitro and in vivo. Pancreas 42: 223-229, 2013.

11. Appari M, Babu KR, Kaczorowski A, Gross W, and Herr I. Sulforaphane, quercetin and catechins complement each other in elimination of advanced pancreatic cancer by miR-let-7 induction and K-ras inhibition. Int J Oncol 45: 1391-1400, 2014.

12. Awad HM, Boersma MG, Boeren S, van der Woude H, van Zanden J, van Bladeren PJ, Vervoort J, and Rietjens IM. Identification of o-quinone/quinone methide metabolites of quercetin in a cellular in vitro system. FEBS Lett 520: 30-34, 2002.

13. Bachmann $\mathrm{M}$ and Moroy $\mathrm{T}$. The serine/threonine kinase Pim-1. Int J Biochem Cell Biol 37: 726-730, 2005.

14. Bacon JR, Williamson G, Garner RC, Lappin G, Langouet $\mathrm{S}$, and Bao Y. Sulforaphane and quercetin modulate PhIPDNA adduct formation in human HepG2 cells and hepatocytes. Carcinogenesis 24: 1903-1911, 2003.

15. Bardy G, Virsolvy A, Quignard JF, Ravier MA, Bertrand G, Dalle S, Cros G, Magous R, Richard S, and Oiry C. Quercetin induces insulin secretion by direct activation of L-type calcium channels in pancreatic beta cells. $\mathrm{Br} J$ Pharmacol 169: 1102-1113, 2013.

16. Barotto NN, Lopez CB, Eynard AR, Fernandez Zapico $\mathrm{ME}$, and Valentich MA. Quercetin enhances pretumorous lesions in the NMU model of rat pancreatic carcinogenesis. Cancer Lett 129: 1-6, 1998.

17. Belguise K, Guo S, Yang S, Rogers AE, Seldin DC, Sherr $\mathrm{DH}$, and Sonenshein GE. Green tea polyphenols reverse cooperation between c-Rel and CK2 that induces the aryl hydrocarbon receptor, slug, and an invasive phenotype. Cancer Res 67: 11742-11750, 2007.

18. Bertram K, Valcu CM, Weitnauer M, Linne U, and Gorlach A. NOX1 supports the metabolic remodeling of HepG2 cells. PLoS One 10: e0122002, 2015.

19. Blouin JM, Penot G, Collinet M, Nacfer M, Forest C, Laurent-Puig P, Coumoul X, Barouki R, Benelli C, and Bortoli S. Butyrate elicits a metabolic switch in human colon cancer cells by targeting the pyruvate dehydrogenase complex. Int J Cancer 128: 2591-2601, 2011.

20. Boersma MG, van der Woude H, Bogaards J, Boeren S, Vervoort J, Cnubben NHP, van Iersel MLPS, van Bladeren PJ, and Rietjens IMCM. Regioselectivity of phase 11 metabolism of luteolin and quercetin by UDPglucuronosyl transferases. Chem Res Toxicol 15: 662-670, 2002.

21. Bonkovsky HL. Hepatotoxicity associated with supplements containing Chinese green tea (Camellia sinensis). Ann Intern Med 144: 68-71, 2006.

22. Boots AW, Bast A, and Haenen GR. No role of DTdiaphorase (NQO1) in the protection against oxidized quercetin. FEBS Lett 579: 677-682, 2005.

23. Boots AW, Kubben N, Haenen GR, and Bast A. Oxidized quercetin reacts with thiols rather than with ascorbate: implication for quercetin supplementation. Biochem Biophys Res Commun 308: 560-565, 2003.

24. Boulton DW, Walle UK, and Walle T. Extensive binding of the bioflavonoid quercetin to human plasma proteins. $J$ Pharm Pharmacol 50: 243-249, 1998. 
25. Cairns RA, Harris I, McCracken S, and Mak TW. Cancer cell metabolism. Cold Spring Harb Symp Quant Biol 76: 299-311, 2011.

26. Cairns RA, Harris IS, and Mak TW. Regulation of cancer cell metabolism. Nat Rev Cancer 11: 85-95, 2011.

27. Camenisch G, Alsenz J, van de Waterbeemd $H$, and Folkers G. Estimation of permeability by passive diffusion through Caco-2cell monolayers using the drugs' lipophilicity and molecular weight. Eur J Pharm Sci 6: 317-324, 1998.

28. Cano A, Arnao MB, Williamson G, and Garcia-Conesa MT. Superoxide scavenging by polyphenols: effect of conjugation and dimerization. Redox Report 7: 379-383, 2002.

29. Cao H, Pauff JM, and Hille R. X-ray crystal structure of a xanthine oxidase complex with the flavonoid inhibitor quercetin. J Nat Prod 77: 1693-1699, 2014.

30. Cao J, Han J, Xiao H, Qiao J, and Han M. Effect of tea polyphenol compounds on anticancer drugs in terms of anti-tumor activity, toxicology, and pharmacokinetics. Nutrients 8: 762, 2016.

31. Caro P, Kishan AU, Norberg E, Stanley IA, Chapuy B, Ficarro SB, Polak K, Tondera D, Gounarides J, Yin H, Zhou F, Green MR, Chen L, Monti S, Marto JA, Shipp MA, and Danial NN. Metabolic signatures uncover distinct targets in molecular subsets of diffuse large B cell lymphoma. Cancer Cell 22: 547-560, 2012.

32. Carracedo A, Cantley LC, and Pandolfi PP. Cancer metabolism: fatty acid oxidation in the limelight. Nat Rev Cancer 13: 227-232, 2013.

33. Carrasco-Pozo C, Tan KN, Reyes-Farias M, De La Jara N, Ngo ST, Garcia-Diaz DF, Llanos P, Cires MJ, and Borges K. The deleterious effect of cholesterol and protection by quercetin on mitochondrial bioenergetics of pancreatic beta-cells, glycemic control and inflammation: in vitro and in vivo studies. Redox Biol 9: 229243, 2016.

34. Carvalho KM, Morais TC, de Melo TS, de Castro Brito GA, de Andrade GM, Rao VS, and Santos FA. The natural flavonoid quercetin ameliorates cerulein-induced acute pancreatitis in mice. Biol Pharm Bull 33: 1534-1539, 2010.

35. Chandrasekaran K, Swaminathan K, Chatterjee S, and Dey A. Apoptosis in HepG2 cells exposed to high glucose. Toxicol In Vitro 24: 387-396, 2010.

36. Chantret I, Rodolosse A, Barbat A, Dussaulx E, BrotLaroche E, Zweibaum A, and Rousset M. Differential expression of sucrase-isomaltase in clones isolated from early and late passages of the cell line Caco-2: evidence for glucose-dependent negative regulation. J Cell Sci 107 (Pt 1): 213-225, 1994.

37. Chen Y, Cairns R, Papandreou I, Koong A, and Denko NC. Oxygen consumption can regulate the growth of tumors, a new perspective on the Warburg effect. PLoS One 4: e7033, 2009.

38. Chen Z, Shi T, Zhang L, Zhu P, Deng M, Huang C, Hu T, Jiang L, and Li J. Mammalian drug efflux transporters of the ATP binding cassette (ABC) family in multidrug resistance: a review of the past decade. Cancer Lett 370: 153-164, 2016.

39. Choi EJ, Bae SM, and Ahn WS. Antiproliferative effects of quercetin through cell cycle arrest and apoptosis in human breast cancer MDA-MB-453 cells. Arch Pharm Res 31: 1281-1285, 2008.
40. Chou CC, Yang JS, Lu HF, Ip SW, Lo C, Wu CC, Lin JP, Tang NY, Chung JG, Chou MJ, Teng YH, and Chen DR. Quercetin-mediated cell cycle arrest and apoptosis involving activation of a caspase cascade through the mitochondrial pathway in human breast cancer MCF-7 cells. Arch Pharm Res 33: 1181-1191, 2010.

41. Cianci M, Folli C, Zonta F, Florio P, Berni R, and Zanotti G. Structural evidence for asymmetric ligand binding to transthyretin. Acta Crystallogr D Biol Crystallogr 71: 1582-1592, 2015.

42. Cifuentes-Gomez T, Rodriguez-Mateos A, GonzalezSalvador I, Alanon ME, and Spencer JP. Factors affecting the absorption, metabolism, and excretion of cocoa flavanols in humans. J Agric Food Chem 63: 7615-7623, 2015.

43. Clifford MN, van der Hooft JJ, and Crozier A. Human studies on the absorption, distribution, metabolism, and excretion of tea polyphenols. Am J Clin Nutr 98: 1619S1630S, 2013.

44. Cordero-Herrera I, Martin MA, Goya L, and Ramos S. Cocoa flavonoids attenuate high glucose-induced insulin signalling blockade and modulate glucose uptake and production in human HepG2 cells. Food Chem Toxicol 64: 10-19, 2014.

45. Coskun O, Kanter M, Korkmaz A, and Oter S. Quercetin, a flavonoid antioxidant, prevents and protects streptozotocininduced oxidative stress and beta-cell damage in rat pancreas. Pharmacol Res 51: 117-123, 2005.

46. Costantini S, Di Bernardo G, Cammarota M, Castello G, and Colonna G. Gene expression signature of human HepG2 cell line. Gene 518: 335-345, 2013.

47. Couse JF and Korach KS. Estrogen receptor null mice: what have we learned and where will they lead us? Endocr Rev 20: 358-417, 1999.

48. Cunningham P, Afzal-Ahmed I, and Naftalin RJ. Docking studies show that D-glucose and quercetin slide through the transporter GLUT1. J Biol Chem 281: 5797-5803, 2006.

49. Daniels VW, Smans K, Royaux I, Chypre M, Swinnen JV, and Zaidi N. Cancer cells differentially activate and thrive on de novo lipid synthesis pathways in a low-lipid environment. PLoS One 9: e106913, 2014.

50. Datsyuk OI. [Impact of quercetin on systemic and splanchnic blood circulation in a complex of preoperative preparation in patients, suffering an acute pancreatitis]. Klin Khir 13-15, 2016.

51. Day AJ, Bao Y, Morgan MRA, and Williamson G. Conjugation position of quercetin glucuronides and effect on biological activity. Free Radic Biol Med 29: 1234-1243, 2000.

52. Day AJ, Canada FJ, Diaz JC, Kroon PA, McLauchlan WR, Faulds CB, Plumb GW, Morgan MRA, and Williamson G. Dietary flavonoid and isoflavone glycosides are hydrolysed by the lactase site of lactase phlorizin hydrolase. FEBS Lett 468: 166-170, 2000.

53. Day AJ, Mellon F, Barron D, Sarrazin G, Morgan MR, and Williamson G. Human metabolism of dietary flavonoids: identification of plasma metabolites of quercetin. Free Radic Res 35: 941-952, 2001.

54. Deb G, Thakur VS, Limaye AM, and Gupta S. Epigenetic induction of tissue inhibitor of matrix metalloproteinase-3 by green tea polyphenols in breast cancer cells. Mol Carcinog 54: 485-499, 2015.

55. Del Rio D, Rodriguez-Mateos A, Spencer JP, Tognolini M, Borges G, and Crozier A. Dietary (poly)phenolics in 
human health: structures, bioavailability, and evidence of protective effects against chronic diseases. Antioxid Redox Signal 18: 1818-1892, 2013.

56. Deng XH, Song HY, Zhou YF, Yuan GY, and Zheng FJ. Effects of quercetin on the proliferation of breast cancer cells and expression of survivin in vitro. Exp Ther Med 6: 1155-1158, 2013.

57. Diers AR, Broniowska KA, Chang CF, and Hogg N. Pyruvate fuels mitochondrial respiration and proliferation of breast cancer cells: effect of monocarboxylate transporter inhibition. Biochem J 444: 561-571, 2012.

58. Dihal AA, Tilburgs C, van Erk MJ, Rietjens IM, Woutersen RA, and Stierum RH. Pathway and single gene analyses of inhibited Caco-2 differentiation by ascorbatestabilized quercetin suggest enhancement of cellular processes associated with development of colon cancer. Mol Nutr Food Res 51: 1031-1045, 2007.

59. Dihal AA, van der Woude H, Hendriksen PJ, Charif H, Dekker LJ, Ijsselstijn L, de Boer VC, Alink GM, Burgers PC, Rietjens IM, Woutersen RA, and Stierum RH. Transcriptome and proteome profiling of colon mucosa from quercetin fed F344 rats point to tumor preventive mechanisms, increased mitochondrial fatty acid degradation and decreased glycolysis. Proteomics 8: 45-61, 2008.

60. Dinkova-Kostova AT and Abramov AY. The emerging role of Nrf2 in mitochondrial function. Free Radic Biol Med 88: 179-188, 2015.

61. Doherty GA, Byrne SM, Austin SC, Scully GM, Sadlier DM, Neilan TG, Kay EW, Murray FE, and Fitzgerald DJ. Regulation of the apoptosis-inducing kinase DRAK2 by cyclooxygenase- 2 in colorectal cancer. Br J Cancer 101: 483-491, 2009.

62. Du G, Lin H, Wang M, Zhang S, Wu X, Lu L, Ji L, and $\mathrm{Yu}$ L. Quercetin greatly improved therapeutic index of doxorubicin against 4T1 breast cancer by its opposing effects on HIF-1alpha in tumor and normal cells. Cancer Chemother Pharmacol 65: 277-287, 2010.

63. Du G, Lin H, Yang Y, Zhang S, Wu X, Wang M, Ji L, Lu L, Yu L, and Han G. Dietary quercetin combining intratumoral doxorubicin injection synergistically induces rejection of established breast cancer in mice. Int Immunopharmacol 10: 819-826, 2010.

64. Dupuy F, Tabaries S, Andrzejewski S, Dong Z, Blagih J, Annis MG, Omeroglu A, Gao D, Leung S, Amir E, Clemons M, Aguilar-Mahecha A, Basik M, Vincent EE, St-Pierre J, Jones RG, and Siegel PM. PDK1-dependent metabolic reprogramming dictates metastatic potential in breast cancer. Cell Metab 22: 577-589, 2015.

65. Eisenberg ML, Maker AV, Slezak LA, Nathan JD, Sritharan KC, Jena BP, Geibel JP, and Andersen DK. Insulin receptor (IR) and glucose transporter 2 (GLUT2) proteins form a complex on the rat hepatocyte membrane. Cell Physiol Biochem 15: 51-58, 2005.

66. Ekstrom AM, Serafini M, Nyren O, Wolk A, Bosetti C, and Bellocco R. Dietary quercetin intake and risk of gastric cancer: results from a population-based study in Sweden. Ann Oncol 22: 438-443, 2011.

67. Eleazu CO, Eleazu KC, Chukwuma S, and Essien UN. Review of the mechanism of cell death resulting from streptozotocin challenge in experimental animals, its practical use and potential risk to humans. J Diabetes Metab Disord 12: 60, 2013.

68. Englund G, Rorsman F, Ronnblom A, Karlbom U, Lazorova L, Grasjo J, Kindmark A, and Artursson P. Re- gional levels of drug transporters along the human intestinal tract: co-expression of $\mathrm{ABC}$ and SLC transporters and comparison with Caco-2 cells. Eur J Pharm Sci 29: 269-277, 2006.

69. Escande C, Nin V, Price NL, Capellini V, Gomes AP, Barbosa MT, O'Neil L, White TA, Sinclair DA, and Chini EN. Flavonoid apigenin is an inhibitor of the NAD+ ase CD38: implications for cellular NAD+ metabolism, protein acetylation, and treatment of metabolic syndrome. Diabetes 62: 1084-1093, 2013.

70. Favreau LV and Pickett CB. Transcriptional regulation of the rat NAD(p)H:quinone reductase gene. J Biol Chem 266: 4556-4561, 1991.

71. Ferry DR, Smith A, Malkhandi J, Fyfe DW, Detakats PG, Anderson D, Baker J, and Kerr DJ. Phase I clinical trial of the flavonoid quercetin: pharmacokinetics and evidence for in vivo tyrosine kinase inhibition. Clin Cancer Res 2: 659-668, 1996.

72. Fiorani M, Guidarelli A, Blasa M, Azzolini C, Candiracci M, Piatti E, and Cantoni O. Mitochondria accumulate large amounts of quercetin: prevention of mitochondrial damage and release upon oxidation of the extramitochondrial fraction of the flavonoid. J Nutr Biochem 21: 397-404, 2010.

73. Fujiki H, Suganuma M, Okabe S, Sueoka E, Suga K, Imai K, Nakachi K, and Kimura S. Mechanistic findings of green tea as cancer preventive for humans. Proc Soc Exp Biol Med 220: 225-228, 1999.

74. Galbusera C, Orth P, Fedida D, and Spector T. Superoxide radical production by allopurinol and xanthine oxidase. Biochem Pharmacol 71: 1747-1752, 2006.

75. Galindo P, Rodriguez-Gomez I, Gonzalez-Manzano S, Duenas M, Jimenez R, Menendez C, Vargas F, Tamargo J, Santos-Buelga C, Perez-Vizcaino F, and Duarte J. Glucuronidated quercetin lowers blood pressure in spontaneously hypertensive rats via deconjugation. PLoS One 7: e32673, 2012.

76. Gao $X$ and Schottker B. Reduction-oxidation pathways involved in cancer development: a systematic review of literature reviews. Oncotarget 8: 51888-51906, 2017.

77. Gatzka M, Newton RH, and Walsh CM. Altered thymic selection and increased autoimmunity caused by ectopic expression of DRAK2 during T cell development. J Immunol 183: 285-297, 2009.

78. Gautier-Stein A, Soty M, Chilloux J, Zitoun C, Rajas F, and Mithieux G. Glucotoxicity induces glucose-6phosphatase catalytic unit expression by acting on the interaction of HIF-1alpha with CREB-binding protein. Diabetes 61: 2451-2460, 2012.

79. Gee JM, DuPont MS, Rhodes MJ, and Johnson IT. Quercetin glucosides interact with the intestinal glucose transport pathway. Free Radic Biol Med 25: 19-25, 1998.

80. Gentric G, Mieulet V, and Mechta-Grigoriou F. Heterogeneity in cancer metabolism: new concepts in an old field. Antioxid Redox Signal 26: 462-485, 2017.

81. Geraets L, Moonen HJ, Brauers K, Wouters EF, Bast A, and Hageman GJ. Dietary flavones and flavonoles are inhibitors of poly(ADP-ribose)polymerase-1 in pulmonary epithelial cells. J Nutr 137: 2190-2195, 2007.

82. Gerk PM and Vore M. Regulation of expression of the multidrug resistance-associated protein 2 (MRP2) and its role in drug disposition. J Pharmacol Exp Ther 302: 407415, 2002. 
83. Gledhill JR, Montgomery MG, Leslie AG, and Walker JE Mechanism of inhibition of bovine F1-ATPase by resveratrol and related polyphenols. Proc Natl Acad Sci U S A 104: 13632-13637, 2007.

84. Gnoni GV, Paglialonga G, and Siculella L. Quercetin inhibits fatty acid and triacylglycerol synthesis in rat-liver cells. Eur J Clin Invest 39: 761-768, 2009.

85. Gong L, Zhu L, Wang S, and Zhang Z. Transthyretin regulates the migration and invasion of JEG-3 cells. Oncol Lett 13: 1242-1246, 2017.

86. Govind PT, Suiko M, Sakakibara Y, and Ming CL. Sulfation of flavonoids and other phenolic dietary compounds by the human cytosolic sulfotransferases. Biochem Biophys Res Commun 285: 1175-1179, 2001.

87. Granado-Serrano AB, Martin MA, Bravo L, Goya L, and Ramos S. Quercetin induces apoptosis via caspase activation, regulation of $\mathrm{Bcl}-2$, and inhibition of PI-3-kinase/ Akt and ERK pathways in a human hepatoma cell line (HepG2). J Nutr 136: 2715-2721, 2006.

88. Granado-Serrano AB, Martin MA, Bravo L, Goya L, and Ramos S. Quercetin attenuates TNF-induced inflammation in hepatic cells by inhibiting the NF-kappaB pathway. Nutr Cancer 64: 588-598, 2012.

89. Grassian AR, Metallo CM, Coloff JL, Stephanopoulos G, and Brugge JS. Erk regulation of pyruvate dehydrogenase flux through PDK4 modulates cell proliferation. Genes Dev 25: 1716-1733, 2011.

90. Gugler R, Leschik M, and Dengler HJ. Disposition of quercetin in man after single oral and intravenous doses. Eur J Clin Pharmacol 9: 229-234, 1975.

91. Gunther S, Ruhe C, Derikito MG, Bose G, Sauer H, and Wartenberg M. Polyphenols prevent cell shedding from mouse mammary cancer spheroids and inhibit cancer cell invasion in confrontation cultures derived from embryonic stem cells. Cancer Lett 250: 25-35, 2007.

92. Guo L, Dial S, Shi L, Branham W, Liu J, Fang JL, Green B, Deng H, Kaput J, and Ning B. Similarities and differences in the expression of drug-metabolizing enzymes between human hepatic cell lines and primary human hepatocytes. Drug Metab Dispos 39: 528-538, 2011.

93. Gutmann H, Fricker G, Torok M, Michael S, Beglinger C, and Drewe J. Evidence for different ABC-transporters in Caco-2 cells modulating drug uptake. Pharm Res 16: 402407, 1999.

94. Hah J, Jo I, Chakrabarti R, and Jung CY. Demonstration of an insulin-insensitive storage pool of glucose transporters in rat hepatocytes and HepG2 cells. J Cell Physiol 152: 56-63, 1992.

95. Hanahan D and Weinberg RA. Hallmarks of cancer: the next generation. Cell 144: 646-674, 2011.

96. Hardie DG. AMPK: a target for drugs and natural products with effects on both diabetes and cancer. Diabetes 62: 2164-2172, 2013.

97. Hawes JW, Jaskiewicz J, Shimomura Y, Huang B, Bunting J, Harper ET, and Harris RA. Primary structure and tissuespecific expression of human beta-hydroxyisobutyrylcoenzyme A hydrolase. J Biol Chem 271: 26430-26434, 1996.

98. Hayes JD and Ashford ML. Nrf2 orchestrates fuel partitioning for cell proliferation. Cell Metab 16: 139-141, 2012.

99. Hirayama B, Lostao MP, Panayotova-Heiermann M, Loo DDF, Turk E, and Wright EM. Kinetic and specificity differences between rat, human, and rabbit $\mathrm{Na}+$-glucose cotransporters (SGLT-1). Am J Physiol 270: G919-G926, 1999.
100. Holder S, Zemskova M, Zhang C, Tabrizizad M, Bremer R, Neidigh JW, and Lilly MB. Characterization of a potent and selective small-molecule inhibitor of the PIM1 kinase. Mol Cancer Ther 6: 163-172, 2007.

101. Hong YJ and Mitchell AE. Identification of glutathionerelated quercetin metabolites in humans. Chem Res Toxicol 19: 1525-1532, 2006.

102. Huang D, Ou B, and Prior RL. The chemistry behind antioxidant capacity assays. J Agric Food Chem 53: 18411856, 2005.

103. Hybertson BM, Gao B, Bose SK, and McCord JM. Oxidative stress in health and disease: the therapeutic potential of Nrf2 activation. Mol Aspects Med 32: 234-246, 2011.

104. Ikei S, Ogawa M, and Yamaguchi Y. Blood concentrations of polymorphonuclear leucocyte elastase and interleukin- 6 are indicators for the occurrence of multiple organ failures at the early stage of acute pancreatitis. $J$ Gastroenterol Hepatol 13: 1274-1283, 1998.

105. Ishigure K, Shimomura Y, Murakami T, Kaneko T, Takeda S, Inoue S, Nomoto S, Koshikawa K, Nonami T, and Nakao A. Human liver disease decreases methacrylylCoA hydratase and beta-hydroxyisobutyryl-CoA hydrolase activities in valine catabolism. Clin Chim Acta 312: 115-121, 2001.

106. Ishisaka A, Kawabata K, Miki S, Shiba Y, Minekawa S, Nishikawa T, Mukai R, Terao J, and Kawai Y. Mitochondrial dysfunction leads to deconjugation of quercetin glucuronides in inflammatory macrophages. PLoS One 8: e80843, 2013.

107. Itoh K, Chiba T, Takahashi S, Ishii T, Igarashi K, Katoh Y, Oyake T, Hayashi N, Satoh K, Hatayama I, Yamamoto M, and Nabeshima Y. An Nrf2/small maf heterodimer mediates the induction of phase II detoxifying enzyme genes through antioxidant elements. Biochem Biophys Res Commun 236: 313-322, 1997.

108. Javaid A and Bonkovsky HL. Hepatotoxicity due to extracts of Chinese green tea (Camellia sinensis): a growing concern. J Hepatol 45: 334-335; author reply 335-336, 2006.

109. Jeon SM, Chandel NS, and Hay N. AMPK regulates NADPH homeostasis to promote tumour cell survival during energy stress. Nature 485: 661-665, 2012.

110. Kamaraj S, Vinodhkumar R, Anandakumar P, Jagan S, Ramakrishnan G, and Devaki T. The effects of quercetin on antioxidant status and tumor markers in the lung and serum of mice treated with benzo(a)pyrene. Biol Pharm Bull 30: 2268-2273, 2007.

111. Karim S, Adams DH, and Lalor PF. Hepatic expression and cellular distribution of the glucose transporter family. World J Gastroenterol 18: 6771-6781, 2012.

112. Kawai Y, Garduno L, Theodore M, Yang J, and Arinze IJ. Acetylation-deacetylation of the transcription factor Nrf2 (nuclear factor erythroid 2-related factor 2) regulates its transcriptional activity and nucleocytoplasmic localization. J Biol Chem 286: 7629-7640, 2011.

113. Kawai Y, Nishikawa T, Shiba Y, Saito S, Murota K, Shibata N, Kobayashi M, Kanayama M, Uchida K, and Terao J. Macrophage as a target of quercetin glucuronides in human atherosclerotic arteries: implication in the antiatherosclerotic mechanism of dietary flavonoids. $J$ Biol Chem 283: 9424-9434, 2008.

114. Kellett GL, Brot-Laroche E, Mace OJ, and Leturque A. Sugar absorption in the intestine: the role of GLUT2. Апnи Rev Nutr 28: 35-54, 2008. 
115. Kellogg EW, III and Fridovich I. Superoxide, hydrogen peroxide, and singlet oxygen in lipid peroxidation by a xanthine oxidase system. J Biol Chem 250: 8812-8817, 1975.

116. Kerimi A, Jailani F, and Williamson G. Modulation of cellular glucose metabolism in human HepG2 cells by combinations of structurally related flavonoids. Mol Nutr Food Res 59: 894-906, 2015.

117. Kerimi A and Williamson G. At the interface of antioxidant signalling and cellular function: key polyphenol effects. Mol Nutr Food Res 60: 1770-1788, 2016.

118. This reference has been deleted.

119. Kim GN and Jang HD. Protective mechanism of quercetin and rutin using glutathione metabolism on $\mathrm{HO}$-induced oxidative stress in HepG2 cells. Ann N Y Acad Sci 1171: 530-537, 2009.

120. Kim JH, Kim MJ, Choi KC, and Son J. Quercetin sensitizes pancreatic cancer cells to TRAIL-induced apoptosis through JNK-mediated cFLIP turnover. Int J Biochem Cell Biol 78: 327-334, 2016.

121. Kim MJ, Ryu GR, Chung JS, Sim SS, Min DS, Rhie DJ, Yoon SH, Hahn SJ, Kim MS, and Jo YH. Protective effects of epicatechin against the toxic effects of streptozotocin on rat pancreatic islets: in vivo and in vitro. Pancreas 26: 292-299, 2003.

122. Kim MJ, Ryu GR, Kang JH, Sim SS, Min DS, Rhie DJ, Yoon SH, Hahn SJ, Jeong IK, Hong KJ, Kim MS, and Jo YH. Inhibitory effects of epicatechin on interleukin-1betainduced inducible nitric oxide synthase expression in RINm5F cells and rat pancreatic islets by down-regulation of NF-kappaB activation. Biochem Pharmacol 68: 17751785, 2004.

123. Kluth D, Banning A, Paur I, Blomhoff R, and BrigeliusFlohe R. Modulation of pregnane X receptor- and electrophile responsive element-mediated gene expression by dietary polyphenolic compounds. Free Radic Biol Med 42: 315-325, 2007.

124. Konig J, Nies AT, Cui YH, Leier I, and Keppler D. Conjugate export pumps of the multidrug resistance protein (MRP) family: localization, substrate specificity, and MRP2-mediated drug resistance. Biochim Biophys Acta Biomemb 1461: 377-394, 1999.

125. Kroon PA, Clifford MN, Crozier A, Day AJ, Donovan JL, Manach C, and Williamson G. How should we assess the effects of exposure to dietary polyphenols in vitro? Am J Clin Nutr 80: 15-21, 2004.

126. Kurbitz C, Heise D, Redmer T, Goumas F, Arlt A, Lemke J, Rimbach G, Kalthoff H, and Trauzold A. Epicatechin gallate and catechin gallate are superior to epigallocatechin gallate in growth suppression and antiinflammatory activities in pancreatic tumor cells. Cancer Sci 102: 728-734, 2011.

127. Kushima Y, Iida K, Nagaoka Y, Kawaratani Y, Shirahama T, Sakaguchi M, Baba K, Hara Y, and Uesato S. Inhibitory effect of (-)-epigallocatechin and (-)epigallocatechin gallate against heregulin beta1-induced migration/invasion of the MCF-7 breast carcinoma cell line. Biol Pharm Bull 32: 899-904, 2009.

128. Kwon O, Eck P, Chen S, Corpe CP, Lee JH, Kruhlak M, and Levine $M$. Inhibition of the intestinal glucose transporter GLUT2 by flavonoids. FASEB $J$ 21: 366-377, 2007.

129. Lee KW, Kang NJ, Heo YS, Rogozin EA, Pugliese A, Hwang MK, Bowden GT, Bode AM, Lee HJ, and Dong Z.
Raf and MEK protein kinases are direct molecular targets for the chemopreventive effect of quercetin, a major flavonol in red wine. Cancer Res 68: 946-955, 2008.

130. Lee YK and Park OJ. Regulation of mutual inhibitory activities between AMPK and Akt with quercetin in MCF7 breast cancer cells. Oncol Rep 24: 1493-1497, 2010.

131. Lemmens KJ, Vrolijk MF, Bouwman FG, van der Vijgh WJ, Bast A, and Haenen GR. The minor structural difference between the antioxidants quercetin and $4^{\prime} \mathrm{O}$ methylquercetin has a major impact on their selective thiol toxicity. Int J Mol Sci 15: 7475-7484, 2014.

132. Li C, Zhang WJ, Choi J, and Frei B. Quercetin affects glutathione levels and redox ratio in human aortic endothelial cells not through oxidation but formation and cellular export of quercetin-glutathione conjugates and upregulation of glutamate-cysteine ligase. Redox Biol 9: 220-228, 2016.

133. Li JM, Wang W, Fan CY, Wang MX, Zhang X, Hu QH, and Kong LD. Quercetin preserves beta -cell mass and function in fructose-induced hyperinsulinemia through modulating pancreatic Akt/FoxO1 activation. Evid Based Complement Alternat Med 2013: 303902, 2013.

134. Li L, Stanton JD, Tolson AH, Luo Y, and Wang H. Bioactive terpenoids and flavonoids from Ginkgo biloba extract induce the expression of hepatic drug-metabolizing enzymes through pregnane $\mathrm{X}$ receptor, constitutive androstane receptor, and aryl hydrocarbon receptor-mediated pathways. Pharm Res 26: 872-882, 2009.

135. Li SZ, Qiao SF, Zhang JH, and Li K. Quercetin increase the chemosensitivity of breast cancer cells to doxorubicin via PTEN/Akt pathway. Anticancer Agents Med Chem 15: 1185-1189, 2015.

136. Li W, Chen C, Zhao X, Ye H, Zhao Y, Fu Z, Pan W, Zheng S, Wei L, Nong T, Li Z, and Chen R. HIF-2alpha regulates non-canonical glutamine metabolism via activation of $\mathrm{PI} 3 \mathrm{~K} / \mathrm{mTORC} 2$ pathway in human pancreatic ductal adenocarcinoma. J Cell Mol Med 2017. DOI: 10.1111/jcmm. 13202

137. Liang JH, Li YN, Qi JS, and Jia XX. Peroxynitriteinduced protein nitration is responsible for renal mitochondrial damage in diabetic rat. $J$ Endocrinol Invest 33: 140-146, 2010.

138. Lim JH, Luo C, Vazquez F, and Puigserver P. Targeting mitochondrial oxidative metabolism in melanoma causes metabolic compensation through glucose and glutamine utilization. Cancer Res 74: 3535-3545, 2014.

139. Lin CL and Lin JK. Epigallocatechin gallate (EGCG) attenuates high glucose-induced insulin signaling blockade in human hepG2 hepatoma cells. Mol Nutr Food Res 52: 930-939, 2008.

140. Lin S, Zhang G, Liao Y, Pan J, and Gong D. Dietary flavonoids as xanthine oxidase inhibitors: structureaffinity and structure-activity relationships. J Agric Food Chem 63: 7784-7794, 2015.

141. Lv Q, Meng XF, He FF, Chen S, Su H, Xiong J, Gao P, Tian XJ, Liu JS, Zhu ZH, Huang K, and Zhang C. High serum uric acid and increased risk of type 2 diabetes: a systemic review and meta-analysis of prospective cohort studies. PLoS One 8: e56864, 2013.

142. Magesh S, Chen Y, and Hu L. Small molecule modulators of Keap1-Nrf2-ARE pathway as potential preventive and therapeutic agents. Med Res Rev 32: 687-726, 2012.

143. Manach C, Williamson G, Morand C, Scalbert A, and Remesy C. Bioavailability and bioefficacy of polyphenols 
in humans. I. Review of 97 bioavailability studies. Am J Clin Nutr 81: 230S-242S, 2005.

144. This reference has been deleted.

145. Mao J, Qiao X, Luo H, and Wu J. Transgenic drak2 overexpression in mice leads to increased $\mathrm{T}$ cell apoptosis and compromised memory $\mathrm{T}$ cell development. J Biol Chem 281: 12587-12595, 2006.

146. Marroquin LD, Hynes J, Dykens JA, Jamieson JD, and Will Y. Circumventing the Crabtree effect: replacing media glucose with galactose increases susceptibility of HepG2 cells to mitochondrial toxicants. Toxicol Sci 97: 539-547, 2007.

147. Martin HJ, Kornmann F, and Fuhrmann GF. The inhibitory effects of flavonoids and antiestrogens on the Glut 1 glucose transporter in human erythrocytes. Chem Biol Interact 146: 225-235, 2003.

148. Martin MA, Fernandez-Millan E, Ramos S, Bravo L, and Goya L. Cocoa flavonoid epicatechin protects pancreatic beta cell viability and function against oxidative stress. Mol Nutr Food Res 58: 447-456, 2014.

149. Matsumoto H, Ikoma Y, Sugiura M, Yano M, and Hasegawa Y. Identification and quantification of the conjugated metabolites derived from orally administered hesperidin in rat plasma. J Agric Food Chem 52: 66536659, 2004.

150. Maurya AK and Vinayak M. Anticarcinogenic action of quercetin by downregulation of phosphatidylinositol 3kinase (PI3K) and protein kinase $\mathrm{C}$ (PKC) via induction of p53 in hepatocellular carcinoma (HepG2) cell line. Mol Biol Rep 42: 1419-1429, 2015.

151. Mazzanti G, Menniti-Ippolito F, Moro PA, Cassetti F, Raschetti R, Santuccio C, and Mastrangelo S. Hepatotoxicity from green tea: a review of the literature and two unpublished cases. Eur J Clin Pharmacol 65: 331-341, 2009.

152. Mazzarelli P, Pucci S, Bonanno E, Sesti F, Calvani M, and Spagnoli LG. Carnitine palmitoyltransferase I in human carcinomas: a novel role in histone deacetylation? Cancer Biol Ther 6: 1606-1613, 2007.

153. McGargill MA, Wen BG, Walsh CM, and Hedrick SM. A deficiency in Drak2 results in a $\mathrm{T}$ cell hypersensitivity and an unexpected resistance to autoimmunity. Immunity 21: 781-791, 2004.

154. McLarty J, Bigelow RL, Smith M, Elmajian D, Ankem M, and Cardelli JA. Tea polyphenols decrease serum levels of prostate-specific antigen, hepatocyte growth factor, and vascular endothelial growth factor in prostate cancer patients and inhibit production of hepatocyte growth factor and vascular endothelial growth factor in vitro. Cancer Prev Res (Phila) 2: 673-682, 2009.

155. Meissen JK, Hirahatake KM, Adams SH, and Fiehn O. Temporal metabolomic responses of cultured HepG2 liver cells to high fructose and high glucose exposures. Metabolomics 11: 707-721, 2015.

156. Menendez C, Duenas M, Galindo P, Gonzalez-Manzano S, Jimenez R, Moreno L, Zarzuelo MJ, Rodriguez-Gomez I, Duarte J, Santos-Buelga C, and Perez-Vizcaino F. Vascular deconjugation of quercetin glucuronide: the flavonoid paradox revealed? Mol Nutr Food Res 55: 17801790, 2011.

157. Mennen LI, Sapinho D, Ito H, Bertrais S, Galan P, Hercberg S, and Scalbert A. Urinary flavonoids and phenolic acids as biomarkers of intake for polyphenol-rich foods. Br J Nutr 96: 191-198, 2006.
158. Meredith D and Christian HC. The SLC16 monocaboxylate transporter family. Xenobiotica 38: 10721106, 2008.

159. Meyers MB, Scotto KW, and Sirotnak FM. P-glycoprotein content and mediation of vincristine efflux: correlation with the level of differentiation in luminal epithelium of mouse small intestine. Cancer Commun 3: 159-165, 1991.

160. Mitaine-Offer AC, Hornebeck W, Sauvain M, and ZechesHanrot M. Triterpenes and phytosterols as human leucocyte elastase inhibitors. Planta Med 68: 930-932, 2002.

161. Mitsuishi Y, Taguchi K, Kawatani Y, Shibata T, Nukiwa T, Aburatani H, Yamamoto M, and Motohashi H. Nrf2 redirects glucose and glutamine into anabolic pathways in metabolic reprogramming. Cancer Cell 22: 66-79, 2012.

162. Moarefi I, LaFevre-Bernt M, Sicheri F, Huse M, Lee CH, Kuriyan J, and Miller WT. Activation of the Src-family tyrosine kinase Hck by SH3 domain displacement. Nature 385: 650-653, 1997.

163. Moreira L, Araujo I, Costa T, Correia-Branco A, Faria A, Martel F, and Keating E. Quercetin and epigallocatechin gallate inhibit glucose uptake and metabolism by breast cancer cells by an estrogen receptor-independent mechanism. Exp Cell Res 319: 1784-1795, 2013.

164. Mostafavi-Pour Z, Ramezani F, Keshavarzi F, and Samadi $\mathrm{N}$. The role of quercetin and vitamin $\mathrm{C}$ in Nrf2-dependent oxidative stress production in breast cancer cells. Oncol Lett 13: 1965-1973, 2017.

165. Mu C, Jia P, Yan Z, Liu X, Li X, and Liu H. Quercetin induces cell cycle G1 arrest through elevating Cdk inhibitors p21 and p27 in human hepatoma cell line (HepG2). Methods Find Exp Clin Pharmacol 29: 179-183, 2007.

166. Mullen W, Boitier A, Stewart AJ, and Crozier A. Flavonoid metabolites in human plasma and urine after the consumption of red onions: analysis by liquid chromatography with photodiode array and full scan tandem mass spectrometric detection. J Chromatogr A 1058: 163-168, 2004.

167. Mullen W, Edwards CA, and Crozier A. Absorption, excretion and metabolite profiling of methyl-, glucuronyl-, glucosyl- and sulpho-conjugates of quercetin in human plasma and urine after ingestion of onions. Br J Nutr 96: 107-116, 2006.

168. This reference has been deleted.

169. Murakami S, Muramatsu M, and Otomo S. Inhibition of gastric $\mathrm{H}+, \mathrm{K}(+)-A T P a s e$ by quercetin. J Enzyme Inhib 5: 293-298, 1992.

170. Musonda CA and Chipman JK. Quercetin inhibits hydrogen peroxide $\left(\mathrm{H}_{2} \mathrm{O}_{2}\right)$-induced NF-kappaB DNA binding activity and DNA damage in HepG2 cells. Carcinogenesis 19: 1583-1589, 1998.

171. Musonda CA, Helsby N, and Chipman JK. Effects of quercetin on drug metabolizing enzymes and oxidation of 2',7-dichlorofluorescin in HepG2 cells. Hum Exp Toxicol 16: 700-708, 1997.

172. Mutch DM, Crespy V, Clough J, Henderson CJ, Lariani S, Mansourian R, Moulin J, Wolf CR, and Williamson G. Hepatic cytochrome P-450 reductase-null mice show reduced transcriptional response to quercetin and reveal physiological homeostasis between jejunum and liver. Am J Physiol Gastrointest Liver Physiol 291: G63-G72, 2006.

173. Mylona E, Magkou C, Giannopoulou I, Agrogiannis G, Markaki S, Keramopoulos A, and Nakopoulou L. Expression of tissue inhibitor of matrix metalloproteinases 
(TIMP)-3 protein in invasive breast carcinoma: relation to tumor phenotype and clinical outcome. Breast Cancer Res 8: R57, 2006.

174. Nakajima K, Yamauchi K, Shigematsu S, Ikeo S, Komatsu M, Aizawa T, and Hashizume K. Selective attenuation of metabolic branch of insulin receptor downsignaling by high glucose in a hepatoma cell line, HepG2 cells. J Biol Chem 275: 20880-20886, 2000.

175. Natsume Y, Ito S, Satsu H, and Shimizu M. Protective effect of quercetin on ER stress caused by calcium dynamics dysregulation in intestinal epithelial cells. Toxicology 258: 164-175, 2009.

176. Natsume Y, Kadota K, Satsu H, and Shimizu M. Effect of quercetin on the gene expression profile of the mouse intestine. Biosci Biotechnol Biochem 73: 722-725, 2009.

177. Navarro VJ, Khan I, Bjornsson E, Seeff LB, Serrano J, and Hoofnagle JH. Liver injury from herbal and dietary supplements. Hepatology 65: 363-373, 2017.

178. Nelson LE, Valentine RJ, Cacicedo JM, Gauthier MS, Ido $\mathrm{Y}$, and Ruderman NB. A novel inverse relationship between metformin-triggered AMPK-SIRT1 signaling and p53 protein abundance in high glucose-exposed HepG2 cells. Am J Physiol Cell Physiol 303: C4-C13, 2012.

179. Notas G, Nifli AP, Kampa M, Pelekanou V, Alexaki VI, Theodoropoulos P, Vercauteren J, and Castanas E. Quercetin accumulates in nuclear structures and triggers specific gene expression in epithelial cells. J Nutr Biochem 23: 656-666, 2012.

180. Nwaeburu CC, Bauer N, Zhao Z, Abukiwan A, Gladkich J, Benner A, and Herr I. Up-regulation of microRNA let$7 \mathrm{c}$ by quercetin inhibits pancreatic cancer progression by activation of Numbl. Oncotarget 7: 58367-58380, 2016.

181. Ohno $S$ and Nakajin S. Determination of mRNA expression of human UDP-glucuronosyltransferases and application for localization in various human tissues by real-time reverse transcriptase-polymerase chain reaction. Drug Metab Dispos 37: 32-40, 2009.

182. Ono T, Tsuruta R, Fujita M, Aki HS, Kutsuna S, Kawamura Y, Wakatsuki J, Aoki T, Kobayashi C, Kasaoka S, Maruyama I, Yuasa M, and Maekawa T. Xanthine oxidase is one of the major sources of superoxide anion radicals in blood after reperfusion in rats with forebrain ischemia/ reperfusion. Brain Res 1305: 158-167, 2009.

183. Osburn WO, Wakabayashi N, Misra V, Nilles T, Biswal S, Trush MA, and Kensler TW. Nrf2 regulates an adaptive response protecting against oxidative damage following diquat-mediated formation of superoxide anion. Arch Biochem Biophys 454: 7-15, 2006.

184. Pang J, Xi C, Dai Y, Gong H, and Zhang TM. Altered expression of base excision repair genes in response to high glucose-induced oxidative stress in HepG2 hepatocytes. Med Sci Monit 18: BR281-BR285, 2012.

185. Papandreou I, Krishna C, Kaper F, Cai D, Giaccia AJ, and Denko NC. Anoxia is necessary for tumor cell toxicity caused by a low-oxygen environment. Cancer Res 65: 3171-3178, 2005.

186. Paranjpe A and Srivenugopal KS. Degradation of NFkappaB, p53 and other regulatory redox-sensitive proteins by thiol-conjugating and -nitrosylating drugs in human tumor cells. Carcinogenesis 34: 990-1000, 2013.

187. Park $\mathrm{H}$ and Jeoung NH. Inflammation increases pyruvate dehydrogenase kinase 4 (PDK4) expression via the Jun NTerminal Kinase ( JNK) pathway in $\mathrm{C} 2 \mathrm{C} 12$ cells. Biochem Biophys Res Commun 469: 1049-1054, 2016.
188. Pereira-Caro G, Borges G, Ky I, Ribas A, Calani L, Del Rio D, Clifford MN, Roberts SA, and Crozier A. In vitro colonic catabolism of orange juice (poly)phenols. Mol Nutr Food Res 59: 465-475, 2015.

189. Perez-Jimenez J, Hubert J, Hooper L, Cassidy A, Manach C, Williamson G, and Scalbert A. Urinary metabolites as biomarkers of polyphenol intake in humans: a systematic review. Am J Clin Nutr 92: 801-809, 2010.

190. Perez-Vizcaino F and Duarte J. Flavonols and cardiovascular disease. Mol Aspects Med 31: 478-494, 2010.

191. Perez A, Gonzalez-Manzano S, Jimenez R, Perez-Abud R, Haro JM, Osuna A, Santos-Buelga C, Duarte J, and Perezand Vizcaino $\mathrm{F}$. The flavonoid quercetin induces acute vasodilator effects in healthy volunteers: correlation with beta-glucuronidase activity. Pharmacol Res 89: 11-18, 2014.

192. Petri N, Tannergren C, Holst B, Mellon FA, Bao Y, Plumb GW, Bacon J, O'Leary KA, Kroon PA, Knutson L, Forsell $\mathrm{P}$, Eriksson T, Lennernas H, and Williamson G. Absorption/metabolism of sulforaphane and quercetin, and regulation of phase ii enzymes, in human jejunum in vivo. Drug Metab Dispos 31: 805-813, 2003.

193. Piconi L, Quagliaro L, and Ceriello A. Oxidative stress in diabetes. Clin Chem Lab Med 41: 1144-1149, 2003.

194. Pimpao RC, Dew T, Figueira ME, McDougall GJ, Stewart D, Ferreira RB, Santos CN, and Williamson G. Urinary metabolite profiling identifies novel colonic metabolites and conjugates of phenolics in healthy volunteers. $\mathrm{Mol}$ Nutr Food Res 58: 1414-1425, 2014.

195. Pimpao RC, Ventura MR, Ferreira RB, Williamson G, and Santos CN. Phenolic sulfates as new and highly abundant metabolites in human plasma after ingestion of a mixed berry fruit puree. Br J Nutr 113: 454-463, 2015.

196. Pollard SE, Kuhnle GG, Vauzour D, Vafeiadou K, Tzounis X, Whiteman M, Rice-Evans C, and Spencer JP. The reaction of flavonoid metabolites with peroxynitrite. Biochem Biophys Res Commun 350: 960-968, 2006.

197. Postic C, Burcelin R, Rencurel F, Pegorier JP, Loizeau M, Girard J, and Leturque A. Evidence for a transient inhibitory effect of insulin on GLUT2 expression in the liver: studies in vivo and in vitro. Biochem J 293 (Pt 1): 119-124, 1993.

198. Price KR and Rhodes MJC. Analysis of the major flavonol glycosides present in four varieties of onion (Allium cepa) and changes in composition resulting from autolysis. J Sci Food Agric 74: 331-339, 1996.

199. Pucci S, Zonetti MJ, Fisco T, Polidoro C, Bocchinfuso G, Palleschi A, Novelli G, Spagnoli LG, and Mazzarelli P. Carnitine palmitoyl transferase-1A (CPT1A): a new tumor specific target in human breast cancer. Oncotarget 7: 19982-19996, 2016.

200. Quagliaro L, Piconi L, Assaloni R, Da RR, Szabo C, and Ceriello A. Primary role of superoxide anion generation in the cascade of events leading to endothelial dysfunction and damage in high glucose treated HUVEC. Nutr Metab Cardiovasc Dis 17: 257-267, 2007.

201. Ramos-Gomex M, Kwak M-K, Dolan PM, Itoh K, Yamamoto M, Talalay P, and Kensler TW. Sensitivity to carcinogenesis is increased and chemoprotective efficacy of enzyme inducers is lost in nrf2 transcription factordeficient mice. PNAS 98: 3410-3415, 2001.

202. Ranganathan S, Halagowder D, and Sivasithambaram ND. Quercetin suppresses twist to induce apoptosis in MCF-7 breast cancer cells. PLoS One 10: e0141370, 2015. 
203. Rayamajhi N, Kim SK, Go H, Joe Y, Callaway Z, Kang JG, Ryter SW, and Chung HT. Quercetin induces mitochondrial biogenesis through activation of $\mathrm{HO}-1$ in HepG2 cells. Oxid Med Cell Longev 2013: 154279, 2013.

204. Reddy NM, Kleeberger SR, Yamamoto M, Kensler TW, Scollick C, Biswal S, and Reddy SP. Genetic dissection of the Nrf2-dependent redox signaling-regulated transcriptional programs of cell proliferation and cytoprotection. Physiol Genomics 32: 74-81, 2007.

205. Ren XY, Li YN, Qi JS, and Niu T. Peroxynitrite-induced protein nitration contributes to liver mitochondrial damage in diabetic rats. J Diabetes Complications 22: $357-$ 364, 2008.

206. Rohr-Udilova N, Klinglmuller F, Seif M, Hayden H, Bilban M, Pinter M, Stolze K, Sieghart W, PeckRadosavljevic M, and Trauner M. Oxidative stress mediates an increased formation of vascular endothelial growth factor in human hepatocarcinoma cells exposed to erlotinib. Oncotarget 2017.

207. Rossi M, Maiuri L, Fusco MI, Salvati VM, Fuccio A, Auricchio S, Mantei N, Zecca L, Gloor SM, and Semenza G. Lastase persistence versus decline in human adults: multifactorial events are involved in down-regulation after weaning. Gastroenterology 112: 1506-1514, 1997.

208. Ruiz PA, Braune A, Holzlwimmer G, Quintanilla-Fend L, and Haller D. Quercetin inhibits TNF-induced NF-kappaB transcription factor recruitment to proinflammatory gene promoters in murine intestinal epithelial cells. J Nutr 137: 1208-1215, 2007.

209. Ruotolo R, Calani L, Brighenti F, Crozier A, Ottonello S, and Del Rio D. Glucuronidation does not suppress the estrogenic activity of quercetin in yeast and human breast cancer cell model systems. Arch Biochem Biophys 559: 62-67, 2014.

210. Sartor L, Pezzato E, and Garbisa S. (-)Epigallocatechin-3gallate inhibits leukocyte elastase: potential of the phytofactor in hindering inflammation, emphysema, and invasion. J Leukoc Biol 71: 73-79, 2002.

211. Secomb TW, Hsu R, Braun RD, Ross JR, Gross JF, and Dewhirst MW. Theoretical simulation of oxygen transport to tumors by three-dimensional networks of microvessels. Adv Exp Med Biol 454: 629-634, 1998.

212. Seithel A, Karlsson J, Hilgendorf C, Bjorquist A, and Ungell AL. Variability in mRNA expression of ABC- and SLC-transporters in human intestinal cells: comparison between human segments and Caco-2 cells. Eur J Pharm Sci 28: 291-299, 2006.

213. Semenkovich CF, Coleman T, and Goforth R. Physiologic concentrations of glucose regulate fatty acid synthase activity in HepG2 cells by mediating fatty acid synthase mRNA stability. J Biol Chem 268: 6961-6970, 1993.

214. Senger DR, Li D, Jaminet SC, and Cao S. Activation of the Nrf2 cell defense pathway by ancient foods: disease prevention by important molecules and microbes lost from the Modern Western Diet. PLoS One 11: e0148042, 2016.

215. Shi Y and Williamson G. Quercetin lowers plasma uric acid in pre-hyperuricaemic males: a randomised, doubleblinded, placebo-controlled, cross-over trial. $\mathrm{Br} \mathrm{J} \mathrm{Nutr}$ 115: 800-806, 2016.

216. Shimomura Y, Honda T, Goto H, Nonami T, Kurokawa T, Nagasaki M, and Murakami T. Effects of liver failure on the enzymes in the branched-chain amino acid catabolic pathway. Biochem Biophys Res Commun 313: 381-385, 2004.
217. Shimomura Y, Murakami T, Nakai N, Huang B, Hawes JW, and Harris RA. 3-hydroxyisobutyryl-CoA hydrolase. Methods Enzymol 324: 229-240, 2000.

218. Sicheri F, Moarefi I, and Kuriyan J. Crystal structure of the Src family tyrosine kinase Hck. Nature 385: 602-609, 1997.

219. Siddique HR, Liao DJ, Mishra SK, Schuster T, Wang L, Matter B, Campbell PM, Villalta P, Nanda S, Deng Y, and Saleem M. Epicatechin-rich cocoa polyphenol inhibits Kras-activated pancreatic ductal carcinoma cell growth in vitro and in a mouse model. Int J Cancer 131: 17201731, 2012.

220. Sies H. Total antioxidant capacity: appraisal of a concept. J Nutr 137: 1493-1495, 2007.

221. Singh A, Bodas M, Wakabayashi N, Bunz F, and Biswal $\mathrm{S}$. Gain of Nrf2 function in non-small-cell lung cancer cells confers radioresistance. Antioxid Redox Signal 13: 1627-1637, 2010.

222. Singh A, Boldin-Adamsky S, Thimmulappa RK, Rath SK, Ashush H, Coulter J, Blackford A, Goodman SN, Bunz F, Watson WH, Gabrielson E, Feinstein E, and Biswal S. RNAi-mediated silencing of nuclear factor erythroid-2related factor 2 gene expression in non-small cell lung cancer inhibits tumor growth and increases efficacy of chemotherapy. Cancer Res 68: 7975-7984, 2008.

223. Singh A, Wu H, Zhang P, Happel C, Ma J, and Biswal S. Expression of ABCG2 (BCRP) is regulated by Nrf2 in cancer cells that confers side population and chemoresistance phenotype. Mol Cancer Ther 9: 2365-2376, 2010.

224. Singh B, Mense SM, Bhat NK, Putty S, Guthiel WA, Remotti F, and Bhat HK. Dietary quercetin exacerbates the development of estrogen-induced breast tumors in female ACI rats. Toxicol Appl Pharmacol 247: 83-90, 2010.

225. Smirnova NA, Kaidery NA, Hushpulian DM, Rakhman, II, Poloznikov AA, Tishkov VI, Karuppagounder SS, Gaisina IN, Pekcec A, Leyen KV, Kazakov SV, Yang L, Thomas B, Ratan RR, and Gazaryan IG. Bioactive flavonoids and catechols as Hif1 and Nrf2 protein stabilizers-implications for Parkinson's disease. Aging Dis 7: 745-762, 2016.

226. Srivastava N, Kollipara RK, Singh DK, Sudderth J, Hu Z, Nguyen H, Wang S, Humphries CG, Carstens R, Huffman KE, DeBerardinis RJ, and Kittler R. Inhibition of cancer cell proliferation by PPARgamma is mediated by a metabolic switch that increases reactive oxygen species levels. Cell Metab 20: 650-661, 2014.

227. Steiner J, Davis J, McClellan J, Enos R, Carson J, Fayad R, Nagarkatti M, Nagarkatti P, Altomare D, Creek K, and Murphy E. Dose-dependent benefits of quercetin on tumorigenesis in the C3(1)/SV40Tag transgenic mouse model of breast cancer. Cancer Biol Ther 15: 1456-1467, 2014.

228. Stevens JF and Maier CS. The chemistry of gut microbial metabolism of polyphenols. Phytochem Rev 1-20, 2016.

229. Sugino K, Nakamura Y, Muramatsu Y, Hata Y, Shibuya $\mathrm{K}$, and Homma S. Analysis of blood neutrophil elastase, glutathione levels and pathological findings in postoperative acute exacerbation of idiopathic pulmonary fibrosis associated with lung cancer: two case reports. Mol Clin Oncol 5: 402-406, 2016.

230. Sun D, Lennernas H, Welage LS, Barnett JL, Landowski CP, Foster D, Fleisher D, Lee KD, and Amidon GL. Comparison of human duodenum and Caco-2 gene ex- 
pression profiles for 12,000 gene sequences tags and correlation with permeability of 26 drugs. Pharm Res 19: 1400-1416, 2002.

231. Suzuki T and Hara H. Quercetin enhances intestinal barrier function through the assembly of zonula [corrected] occludens-2, occludin, and claudin- 1 and the expression of claudin-4 in Caco-2 cells. J Nutr 139: 965-974, 2009.

232. Syu JP, Chi JT, and Kung HN. Nrf2 is the key to chemotherapy resistance in MCF7 breast cancer cells under hypoxia. Oncotarget 7: 14659-14672, 2016.

233. Tachibana H, Koga K, Fujimura Y, and Yamada K. A receptor for green tea polyphenol EGCG. Nat Struct Mol Biol 11: 380-381, 2004.

234. Takanaga H, Chaudhuri B, and Frommer WB. GLUT1 and GLUT9 as major contributors to glucose influx in HepG2 cells identified by a high sensitivity intramolecular FRET glucose sensor. Biochim Biophys Acta 1778: 10911099, 2008.

235. Tan J, Wang B, and Zhu L. Regulation of survivin and Bcl-2 in HepG2 cell apoptosis induced by quercetin. Chem Biodivers 6: 1101-1110, 2009.

236. Tan J, Yang HS, and Patel MS. Regulation of mammalian pyruvate dehydrogenase alpha subunit gene expression by glucose in HepG2 cells. Biochem J 336 (Pt 1): 49-56, 1998.

237. Tanigawa S, Fujii M, and Hou DX. Action of Nrf2 and Keap1 in ARE-mediated NQO1 expression by quercetin. Free Radic Biol Med 42: 1690-1703, 2007.

238. Taniguchi K, Nonami T, Nakao A, Harada A, Kurokawa T, Sugiyama S, Fujitsuka N, Shimomura Y, Hutson SM, Harris RA, and Takagi $H$. The valine catabolic pathway in human liver: effect of cirrhosis on enzyme activities. Hepatology 24: 1395-1398, 1996.

239. Terao J, Murota K, and Kawai Y. Conjugated quercetin glucuronides as bioactive metabolites and precursors of aglycone in vivo. Food Funct 2: 11-17, 2011.

240. Terao J, Yamaguchi S, Shirai M, Miyoshi M, Moon JH, Oshima S, Inakuma T, Tsushida T, and Kato Y. Protection by quercetin and quercetin 3-O-beta-glueuronide of peroxynitrite-induced antioxidant consumption in human plasma low-density lipoprotein. Free Radic Res 35: 925931, 2001.

241. Theodoratou E, Kyle J, Cetnarskyj R, Farrington SM, Tenesa A, Barnetson R, Porteous M, Dunlop M, and Campbell H. Dietary flavonoids and the risk of colorectal cancer. Cancer Epidemiol Biomarkers Prev 16: 684-693, 2007.

242. Thomasset SC, Berry DP, Garcea G, Marczylo T, Steward WP, and Gescher AJ. Dietary polyphenolic phytochemicals-promising cancer chemopreventive agents in humans? A review of their clinical properties. Int $J$ Cancer 120: 451-458, 2007.

243. van DD, Jansen H, and Verhoeven AJ. Glucose increases hepatic lipase expression in HepG2 liver cells through upregulation of upstream stimulatory factors 1 and 2 . Diabetologia 51: 2078-2087, 2008.

244. Vaupel P. Tumor microenvironmental physiology and its implications for radiation oncology. Semin Radiat Oncol 14: 198-206, 2004.

245. Vazquez F, Lim JH, Chim H, Bhalla K, Girnun G, Pierce K, Clish CB, Granter SR, Widlund HR, Spiegelman BM, and Puigserver P. PGC1alpha expression defines a subset of human melanoma tumors with increased mitochondrial capacity and resistance to oxidative stress. Cancer Cell 23: 287-301, 2013.
246. Venugopal R and Jaiswal AK. Nrf1 and Nrf2 positively and c-Fos and Fral negatively regulate the human antioxidant response element-mediated expression of $\mathrm{NAD}(\mathrm{P}) \mathrm{H}$ : quinone oxidoreductase(1) gene. Proc Natl Acad Sci USA 93: 14960-14965, 1996.

247. Vidyashankar S, Sandeep VR, and Patki PS. Quercetin ameliorate insulin resistance and up-regulates cellular antioxidants during oleic acid induced hepatic steatosis in HepG2 cells. Toxicol In Vitro 27: 945-953, 2013.

248. von Kleist L, Michaelis S, Bartho K, Graebner O, Schlief M, Dreger M, Schrey AK, Sefkow M, Kroll F, Koester H, and Luo Y. Identification of potential off-target toxicity liabilities of catechol-O-methyltransferase inhibitors by differential competition capture compound mass spectrometry. J Med Chem 59: 4664-4675, 2016.

249. Vrba J, Kren V, Vacek J, Papouskova B, and Ulrichova J. Quercetin, quercetin glycosides and taxifolin differ in their ability to induce AhR activation and CYP1A1 expression in HepG2 cells. Phytother Res 26: 1746-1752, 2012.

250. Waizenegger J, Lenze D, Luckert C, Seidel A, Lampen A, and Hessel S. Dose-dependent induction of signaling pathways by the flavonoid quercetin in human primary hepatocytes: a transcriptomic study. Mol Nutr Food Res 2015.

251. Wallace DC. Mitochondria and cancer. Nat Rev Cancer 12: 685-698, 2012.

252. Wang H, Tao L, Qi K, Zhang H, Feng D, Wei W, Kong H, Chen T, and Lin Q. Quercetin reverses tamoxifen resistance in breast cancer cells. J BUON 20: 707-713, 2015.

253. Wang J, Ye C, Chen C, Xiong H, Xie B, Zhou J, Chen Y, Zheng S, and Wang L. Glucose transporter GLUT1 expression and clinical outcome in solid tumors: a systematic review and meta-analysis. Oncotarget 8: 1687516886, 2017.

254. Wang MD, Wu H, Fu GB, Zhang HL, Zhou X, Tang L, Dong LW, Qin CJ, Huang S, Zhao LH, Zeng M, Wu MC, Yan HX, and Wang HY. Acetyl-coenzyme A carboxylase alpha promotion of glucose-mediated fatty acid synthesis enhances survival of hepatocellular carcinoma in mice and patients. Hepatology 63: 1272-1286, 2016.

255. Wang P, Heber D, and Henning SM. Quercetin increased bioavailability and decreased methylation of green tea polyphenols in vitro and in vivo. Food Funct 3: 635-642, 2012.

256. Wang RE, Hunt CR, Chen J, and Taylor JS. Biotinylated quercetin as an intrinsic photoaffinity proteomics probe for the identification of quercetin target proteins. Bioorg Med Chem 19: 4710-4720, 2011.

257. Wang X, Wang Z, Liu JZ, Hu JX, Chen HL, Li WL, and Hai CX. Double antioxidant activities of rosiglitazone against high glucose-induced oxidative stress in hepatocyte. Toxicol In Vitro 25: 839-847, 2011.

258. Wang XJ, Sun Z, Villeneuve NF, Zhang S, Zhao F, Li Y, Chen W, Yi X, Zheng W, Wondrak GT, Wong PK, and Zhang DD. Nrf2 enhances resistance of cancer cells to chemotherapeutic drugs, the dark side of Nrf2. Carcinogenesis 29: 1235-1243, 2008.

259. Weijl NI, Elsendoorn TJ, Lentjes EG, Hopman GD, Wipkink-Bakker A, Zwinderman AH, Cleton FJ, and Osanto S. Supplementation with antioxidant micronutrients and chemotherapy-induced toxicity in cancer patients treated with cisplatin-based chemotherapy: a randomised, double-blind, placebo-controlled study. Eur J Cancer 40: 1713-1723, 2004. 
260. Wilkening S, Stahl F, and Bader A. Comparison of primary human hepatocytes and hepatoma cell line Hepg2 with regard to their biotransformation properties. Drug Metab Dispos 31: 1035-1042, 2003.

261. Williamson G. Possible effects of dietary polyphenols on sugar absorption and digestion. Mol Nutr Food Res 57: 48-57, 2013.

262. Williamson G, Barron D, Shimoi $\mathrm{K}$, and Terao J. In vitro biological properties of flavonoid conjugates found in vivo. Free Radic Res 39: 457-469, 2005.

263. Williamson G and Clifford MN. Role of the small intestine, colon and microbiota in determining the metabolic fate of polyphenols. Biochem Pharmacol 139: 24-39, 2017.

264. Winterbourn CC and Metodiewa D. Reactivity of biologically important thiol compounds with superoxide and hydrogen peroxide. Free Radic Biol Med 27: 322-328, 1999.

265. Wong CC, Akiyama Y, Abe T, Lippiat JD, Orfila C, and Williamson G. Carrier-mediated transport of quercetin conjugates: involvement of organic anion transporters and organic anion transporting polypeptides. Biochem Pharmacol 84: 564-570, 2012.

266. Wong CC, Botting NP, Orfila C, Al-Maharik N, and Williamson $\mathrm{G}$. Flavonoid conjugates interact with organic anion transporters (OATs) and attenuate cytotoxicity of adefovir mediated by organic anion transporter 1 (OAT1/ SLC22A6). Biochem Pharmacol 81: 942-949, 2011.

267. Wu X, Sun L, Wang X, Su P, Li Z, Zhang C, Wang Y, Gao P, and Ma R. Breast cancer invasion and metastasis by mPRalpha through the PI3K/Akt signaling pathway. Pathol Oncol Res 22: 471-476, 2016.

268. Xiang M, Namani A, Wu S, and Wang X. Nrf2: bane or blessing in cancer? J Cancer Res Clin Oncol 140: 12511259, 2014.

269. Xue M, Qian Q, Adaikalakoteswari A, Rabbani N, Babaei-Jadidi R, and Thornalley PJ. Activation of NF-E2related factor-2 reverses biochemical dysfunction of endothelial cells induced by hyperglycemia linked to vascular disease. Diabetes 57: 2809-2817, 2008.

270. Xue M, Weickert MO, Qureshi S, Kandala NB, Anwar A, Waldron M, Shafie A, Messenger D, Fowler M, Jenkins G, Rabbani N, and Thornalley PJ. Improved glycemic control and vascular function in overweight and obese subjects by glyoxalase 1 inducer formulation. Diabetes 65: 22822294, 2016.

271. Yamazaki S, Miyoshi N, Kawabata K, Yasuda M, and Shimoi K. Quercetin-3-O-glucuronide inhibits noradrenalinepromoted invasion of MDA-MB-231 human breast cancer cells by blocking beta(2)-adrenergic signaling. Arch Biochem Biophys 557: 18-27, 2014.

272. Yang JH, Shin BY, Han JY, Kim MG, Wi JE, Kim YW, Cho IJ, Kim SC, Shin SM, and Ki SH. Isorhamnetin protects against oxidative stress by activating Nrf2 and inducing the expression of its target genes. Toxicol Appl Pharmacol 274: 293-301, 2014.

273. Yao P, Hao L, Nussler N, Lehmann A, Song F, Zhao J, Neuhaus P, Liu L, and Nussler A. The protective role of $\mathrm{HO}-1$ and its generated products ( $\mathrm{CO}$, bilirubin, and $\mathrm{Fe})$ in ethanol-induced human hepatocyte damage. Am J Physiol Gastrointest Liver Physiol 296: G1318-G1323, 2009.

274. Yao P, Nussler A, Liu L, Hao L, Song F, Schirmeier A, and Nussler N. Quercetin protects human hepatocytes from ethanol-derived oxidative stress by inducing heme oxygenase-1 via the MAPK/Nrf2 pathways. J Hepatol 47: 253-261, 2007.
275. Yokoyama T, Kosaka Y, and Mizuguchi M. Structural insight into the interactions between death-associated protein kinase 1 and natural flavonoids. J Med Chem 58: 7400-7408, 2015.

276. Zang M, Zuccollo A, Hou X, Nagata D, Walsh K, Herscovitz H, Brecher $\mathrm{P}$, Ruderman $\mathrm{NB}$, and Cohen RA. AMP-activated protein kinase is required for the lipidlowering effect of metformin in insulin-resistant human HepG2 cells. J Biol Chem 279: 47898-47905, 2004.

277. Zhang DD and Hannink M. Distinct cysteine residues in Keap1 are required for Keap1-dependent ubiquitination of Nrf2 and for stabilization of Nrf2 by chemopreventive agents and oxidative stress. Mol Cell Biol 23: 8137-8151, 2003.

278. Zhao JL, Zhao J, and Jiao HJ. Synergistic growthsuppressive effects of quercetin and cisplatin on HepG2 human hepatocellular carcinoma cells. Appl Biochem Biotechnol 172: 784-791, 2014.

279. Zhao P, Mao JM, Zhang SY, Zhou ZQ, Tan Y, and Zhang Y. Quercetin induces HepG2 cell apoptosis by inhibiting fatty acid biosynthesis. Oncol Lett 8: 765-769, 2014.

280. Zhao X, Wang Q, Yang S, Chen C, Li X, Liu J, Zou Z, and Cai D. Quercetin inhibits angiogenesis by targeting calcineurin in the xenograft model of human breast cancer. Eur J Pharmacol 781: 60-68, 2016.

281. Zheng J, Wu J, Chen J, Liu J, Lu Y, Huang C, Hu G, Wang X, and Zeng Y. Therapeutic effects of quercetin on early inflammation in hypertriglyceridemia-related acute pancreatitis and its mechanism. Pancreatology 16: 200210, 2016.

282. Zheng Y, Scow JS, Duenes JA, and Sarr MG. Mechanisms of glucose uptake in intestinal cell lines: role of GLUT2. Surgery 151: 13-25, 2012.

283. Zhou J, Li LU, Fang LI, Xie H, Yao W, Zhou X, Xiong Z, Wang LI, Li Z, and Luo F. Quercetin reduces cyclin D1 activity and induces G1 phase arrest in HepG2 cells. Oncol Lett 12: 516-522, 2016.

284. Zhou J, Liang S, Fang L, Chen L, Tang M, Xu Y, Fu A, Yang J, and Wei Y. Quantitative proteomic analysis of HepG2 cells treated with quercetin suggests IQGAP1 involved in quercetin-induced regulation of cell proliferation and migration. OMICS 13: 93-103, 2009.

285. Ziegler K, Tumova S, Kerimi A, and Williamson G. Cellular asymmetric catalysis by UDP-glucuronosyltransferase 1A8 shows functional localization to the basolateral plasma membrane. J Biol Chem 290: 7622-7633, 2015.

286. Zucco F, Batto AF, Bises G, Chambaz J, Chiusolo A, Consalvo R, Cross H, Dal Negro G, de A, I, Fabre G, Guillou F, Hoffman S, Laplanche L, Morel E, PinconRaymond M, Prieto P, Turco L, Ranaldi G, Rousset M, Sambuy Y, Scarino ML, Torreilles F, and Stammati A. An inter-laboratory study to evaluate the effects of medium composition on the differentiation and barrier function of Caco-2 cell lines. Altern Lab Anim 33: 603-618, 2005.

Address correspondence to: Dr. Gary Williamson

School of Food Science and Nutrition University of Leeds

Leeds LS2 9JT

United Kingdom

E-mail: g.williamson@leeds.ac.uk 
Date of first submission to ARS Central, August 17, 2017; date of acceptance, August 18, 2017.

\begin{tabular}{|c|}
\hline 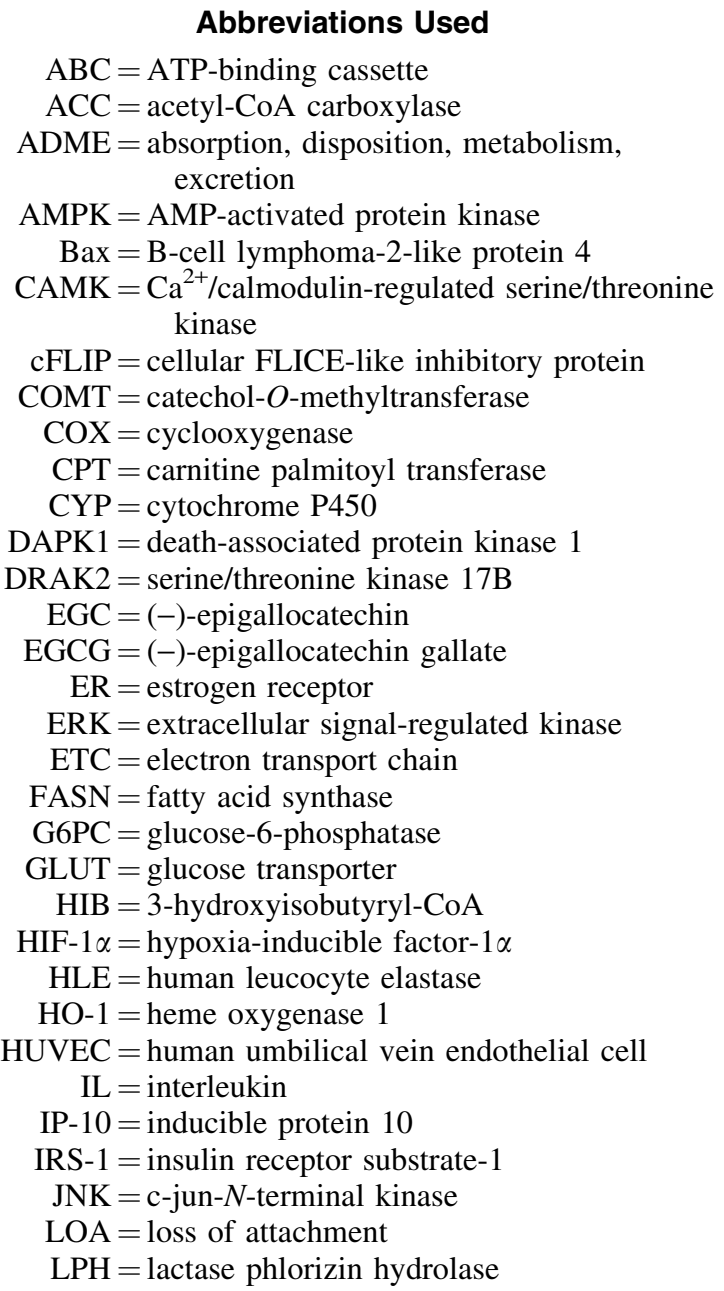 \\
\hline
\end{tabular}

MAPK $=$ mitogen-activated protein kinase

$\mathrm{MCT}=$ monocarboxylate transporter

$\mathrm{MEK}=$ mitogen-activated protein kinase kinase

MIP-2 = macrophage inflammatory protein 2

$\mathrm{MMP}=$ matrix metalloproteinase

$\mathrm{MRP}=$ multidrug resistance-associated protein

$\mathrm{NF}-\kappa \mathrm{B}=$ nuclear factor kappa-light-chain-enhancer of activated B cells

$\mathrm{NO}=$ nitric oxide

NOX1 $=$ NADPH oxidase 1

$\mathrm{NQO} 1=$ quinone reductasequinone oxidoreductase

Nrf2 = nuclear factor (erythroid-derived 2)-like 2

$\mathrm{OAT}=$ organic anion transporter

OATP $=$ organic anion-transporting polypeptide

OXPHOS = oxidative phosphorylation

$\mathrm{PDAC}=$ pancreatic ductal adenocarcinoma

$\mathrm{PDC}=$ pyruvate dehydrogenase complex

$\mathrm{PDK}=$ pyruvate dehydrogenase kinase

$\mathrm{PGC} 1 \alpha=\mathrm{PPAR} \gamma$ coactivator $1 \alpha$

$\mathrm{PhIP}=2$-amino-1-methyl-6-phenylimidazo[4,5-b] pyridine

$\mathrm{PI} 3 \mathrm{~K}=$ phosphatidylinositol-4,5-bisphosphate 3-kinase

$\mathrm{PI} 3 \mathrm{~K}=$ phosphoinositide 3-kinase

$\mathrm{PKC}=$ protein kinase $\mathrm{C}$

$\mathrm{PPAR}=$ peroxisome proliferator-activated receptor

PTEN $=$ phosphatase and tensin homolog

$\mathrm{PTK}=$ protein tyrosine kinase

$\mathrm{RNS}=$ reactive nitrogen species

$\mathrm{ROS}=$ reactive oxygen species

$\mathrm{SIRT} 1=\mathrm{NAD}^{+}$-dependent histone/protein deacetylase sirtuin 1

SULT $=$ sulfotransferase

TCA $=$ tricarboxylic acid

TIMP-3 = tissue inhibitor of matrix metalloproteinase-3

$\mathrm{TNF}=$ tumor necrosis factor

$\mathrm{UGT}=$ uridine diphosphate glucuronosyl transferase

$\mathrm{XOR}=$ xanthine oxidoreductase 